\title{
Nonductal neoplasms of the pancreas
}

\author{
David S Klimstra
}

Department of Pathology, Memorial Sloan Kettering Cancer Center, New York, NY, USA

\begin{abstract}
Although the majority of pancreatic neoplasms are infiltrating ductal adenocarcinomas or other neoplasms with ductal differentiation, neoplasms with acinar, endocrine, mixed, or uncertain differentiation constitute a diverse and distinctive group. The most common and best-characterized nonductal neoplasms are pancreatic endocrine neoplasm, acinar cell carcinoma, pancreatoblastoma, and solid pseudopapillary neoplasm. This review details the clinical and pathologic features of these nonductal neoplasms, highlighting diagnostic criteria including the use of specific immunohistochemical stains to define the cellular differentiation of the neoplasms.

Modern Pathology (2007) 20, S94-S112. doi:10.1038/modpathol.3800686
\end{abstract}

Keywords: pancreas; endocrine; acinar; pancreatoblastoma; solid pseudopapillary

One of the most important features of pancreatic neoplasms, on which their classification in large part is based, is the line(s) of cellular differentiation the neoplasm displays. Most pancreatic epithelial neoplasms recapitulate to some degree one or more of the normal epithelial cell types of the pancreas: ductal, acinar, and endocrine. The vast majority of pancreatic neoplasms (>90\%) have ductal differentiation, including the most common tumor, infiltrating ductal adenocarcinoma, as well as many of the cystic and intraductal neoplasms. The small group of 'nonductal' pancreatic neoplasms includes endocrine and acinar neoplasms as well as those with mixed or undetermined differentiation. These include pancreatic endocrine neoplasms, acinar cell carcinoma and related entities, pancreatoblastoma, and solid-pseudopapillary neoplasm. Many of these entities are highly distinctive pathologically and clinically, and their features differ substantially from the more commonly encountered ductal adenocarcinoma. In addition, they all typically have a solid, hypercellular appearance; thus, they all fall into the same differential diagnosis. Herein are presented the clinical and pathologic features of these uncommon neoplasms.

\section{Pancreatic endocrine neoplasms}

Pancreatic neoplasms in which the predominant line of differentiation is endocrine are designated

Correspondence: Dr DS Klimstra, MD, Department of Pathology, Memorial Sloan Kettering Cancer Center, 1275 York Avenue, New York, NY 10021, USA.

E-mail: klimstrd@mskcc.org

Received and accepted 3 August 2006 'pancreatic endocrine neoplasms' (PENs). The older term 'islet cell tumor' is now discouraged as PENs do not necessarily arise from non-neoplastic islet cells and some produce peptide hormones not encountered in normal islets. PENs are classified into three categories based on size and mitotic rate. PENs measuring less than $0.5 \mathrm{~cm}$ are regarded to be biologically benign and are termed endocrine microadenomas. PENs measuring $0.5 \mathrm{~cm}$ or more and having a relatively low mitotic rate of up to 10 mitoses per 10 high-power fields (50 mitoses per $50 \mathrm{hpf}$ ) are termed welldifferentiated pancreatic endocrine neoplasms, and it is this group that constitutes the majority of PENs that come to clinical attention. Poorly differentiated endocrine carcinomas with more that 10 mitoses per $10 \mathrm{hpf}$ do arise in the pancreas but are very rare.

As pancreatic endocrine microadenomas measure less than $0.5 \mathrm{~cm}$ and are by definition nonfunctional, they rarely come to clinical attention. ${ }^{1,2}$ Patients with multiple endocrine neoplasia, type 1 (MEN1) typically have numerous endocrine microadenomas, in addition to larger PENs. The prevalence of sporadic microadenomas is estimated to be as high as $10 \%$ of the adult population at autopsy when numerous sections of the pancreas are examined; the rate is lower $(1 \%)$ when fewer sections are studied. ${ }^{3,4}$ Most microadenomas are identified incidentally in pancreata resected for other neoplasms or at autopsy. Endocrine microadenomas may occur at any age, but, most are found in adults as their detection usually depends upon resection of a portion of the pancreas for some other reasons. Patients with MEN1 are younger when their PENs are detected. ${ }^{5}$ 


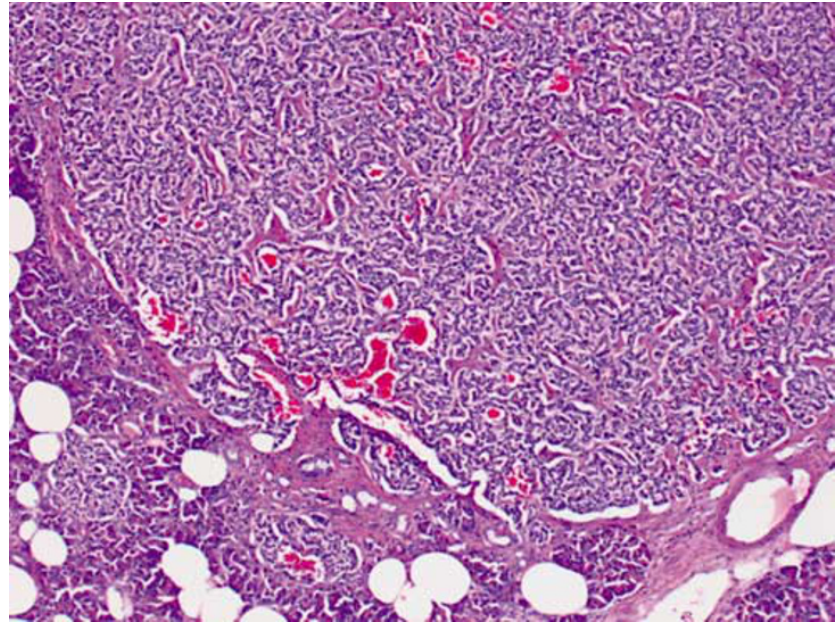

Figure 1 Endocrine microadenoma. This $2 \mathrm{~mm}$ endocrine neoplasm is circumscribed but not encapsulated and consists of ribbons and nests of uniform cells.

The endocrine microadenomas that are recognized grossly are circumscribed but unencapsulated soft tan nodules averaging 1-2 mm. Microscopically, endocrine microadenomas usually have a nesting or trabecular architecture with minimal fibrous stroma between the neoplastic lobules (Figure 1), although hyalinized amyloid-like material may be found. The cells closely resemble normal islet cells, and mitotic figures usually are not identified. By immunohistochemistry, microadenomas express general endocrine markers including chromogranin, synaptophysin, and CD56. Most label for only one or two of the four normal islet peptides, and it is common to find either glucagon or PP labeling in the majority of the cells. ${ }^{4}$ Labeling for ectopic peptides such as VIP or gastrin is uncommon.

The differential diagnosis of endocrine microadenomas includes acinar cell nodules as well as non-neoplastic islets of Langerhans that are either enlarged (islet hyperplasia) or distorted owing to chronic pancreatitis (islet aggregation). Acinar cell nodules $^{6,7}$ are small, circumscribed collections of cytologically altered acinar cells. Careful examination reveals basal polarization of the nuclei and apical cytoplasmic zymogen granules, distinguishing acinar cell nodules from endocrine microadenomas. Because normal non-neoplastic islets vary considerably in size, occasional islets may overlap in size with microadenomas. Furthermore, in chronic pancreatitis there is aggregation of islets as the exocrine elements atrophy, resulting in nodular collections of distorted islets and simulating a neoplasm. ${ }^{8}$ Non-neoplastic islets retain their heterogeneous population of different peptide cell types, and immunohistochemical labeling of non-neoplastic islets for the normal islet peptides (insulin, glucagon, somatostatin, and pancreatic polypeptide (PP)) reveals the presence of all cell types, in roughly normal numbers and distribution.
By contrast, cells expressing one peptide typically predominate in endocrine microadenomas. Because they share many of the histologic features of larger PENs, it is tempting to assume that microadenomas represent an earlier phase in the development of clinically relevant PENs. Certainly, all PENs must pass through a microadenoma stage as they grow to sizes greater than $0.5 \mathrm{~cm}$. However, there are a number of findings including their prevalence, their peptide cell constitution, and their molecular profile that suggest that most microadenomas are not simply smaller versions of PENs. Importantly, it appears likely that most microadenomas do not progress beyond the stage of a small, biologically benign endocrine neoplasm.

Well-differentiated pancreatic endocrine neoplasms constitute one of the more interesting families of pancreatic neoplasms owing to the variety of paraneoplastic syndromes with which they may be associated. They are subclassified as functional or nonfunctional depending upon the presence or absence of such a paraneoplastic syndrome. Functional PENs include insulinomas, glucagonomas, somatostatinomas, gastrinomas, VIPomas (vasoactive intestinal polypeptide-omas), serotonin secreting tumors, and other rare ectopic hormone-producing and mixed hormone-producing entities. A PEN not associated with a clinical syndrome is designated a nonfunctional PEN. It is important to recognize that the designation functional PEN only applies to those neoplasms associated with a corresponding clinical syndrome. ${ }^{1}$ Many other PENs 'function', in the sense that they produce peptide hormones that may be detected in the serum or in the neoplastic cells by immunohistochemistry; 9,10 however, these 'nonsyndromic' PENs are still categorized with the nonfunctional group. An exception to this rule, for historical reasons, is the PP cell PEN or PPoma, ${ }^{11,12}$ a PEN that is demonstrated to produce predominantly PP by immunohistochemistry. Most such PENs also have serum elevations of $\mathrm{PP}$, but there are no specific symptoms attributable to $\mathrm{PP}$, so PPomas are technically nonsyndromic PENs, despite being traditionally classified with the functional group.

PENs constitute $1-2 \%$ of pancreatic neoplasms. ${ }^{1}$ The prevalence of PENs in the general population is about one in $100000 .^{13}$ Although functional PENs were overrepresented in older studies, nonfunctional PENs currently comprise more than half of surgically resected cases. ${ }^{9}$ Among the functional variants, ${ }^{1}$ insulinomas make up $42 \%$, gastrinomas $24 \%$, glucagonomas $14 \%$, VIPomas $10 \%$, somatostatinomas $6 \%$, and the remaining ectopic and multiple hormone-producing neoplasms are rare. ${ }^{14-16}$ PENs are most common between the ages of 40 and $60(\text { mean }=58)^{4,17}$ and are rare in childhood. Overall, both men and women develop PENs with an equal frequency, although there are some differences in the male-to-female ratio among the different functional types. The presenting clinical features 
depend upon the presence and type of any endocrine paraneoplastic syndrome. A detailed description of the clinical features of each syndrome is beyond the scope of this discussion; interested readers are referred to the pertinent sections of the WHO publication (DeLellis RA, Lloyd RV, Heitz PU, Eng C, eds. Pathology and Genetics of Tumours of Endocrine Organs. IARC Press: Lyon, 2004, pp 176-208). Patients with nonfunctional PENs usually present with nonspecific symptoms including abdominal pain or nausea. Rarely PENs compress the bile duct and cause jaundice. Approximately $15 \%$ of nonfunctional PENs are identified incidentally on abdominal imaging studies. ${ }^{18}$ Finally, a sizeable group of patients with PENs present with symptoms related to metastatic disease, usually in the liver.

Some PENs arise in patients with hereditary syndromes including MEN1 and von Hippel-Lindau (VHL) syndromes. Patients with MEN1 typically have multiple endocrine neoplasms in the pancreas, including both microadenomas and PENs, ${ }^{5,19}$ at least one of which is functional. ${ }^{5,19,20}$ Gastrinomas are the most common functional PEN in MEN1 patients, followed by insulinomas, VIPomas, glucagonomas, and PENs producing growth hormone releasing factor and inducing acromegaly. PENs occur in about $5-10 \%$ of patients with VHL syndrome and may be multiple. The majority are nonfunctional ${ }^{21}$ and many $(60 \%)$ have a foamy clear cell appearance. $^{22}$ VHL patients also develop serous cystic neoplasms in the pancreas, and mixed PEN/serous cystic neoplasms also occur, likely representing collision tumors.

PENs occur throughout the pancreas, and about $60 \%$ of PENs arise in the pancreatic tail. ${ }^{4}$ The gross appearance varies widely. Smaller PENs are usually sharply circumscribed or even encapsulated and are composed of uniform red-tan to yellow parenchyma. Larger PENs are multinodular and can grossly demonstrate evidence of invasive growth (Figure 2). Some PENs are very soft whereas others are firm or even sclerotic. Areas of hemorrhage or, less commonly, necrosis may be found. Rarely PENs are grossly cystic, ${ }^{23}$ with a single central locule surrounded by a thin rim of neoplastic parenchyma.

The microscopic appearance of PENs is also highly varied. Most PENs have a relatively circumscribed border, with a fibrotic pseudocapsule partially or entirely surrounding the tumor, but invasive growth is actually quite common. Architecturally, PENs typically have nesting, trabecular, or gyriform patterns, often with different patterns in different regions of the neoplasm (Figure 3). Numerous small vessels, each surrounded by a variable amount of fibrotic stroma, encircle the clusters of neoplastic cells. In some cases, there is little collagen in the stroma, but in others the stroma is densely hyalinized. Amyloid deposition may occur $^{24,25}$ (especially in insulinomas), as may psammomatous calcifications. The cells are usually

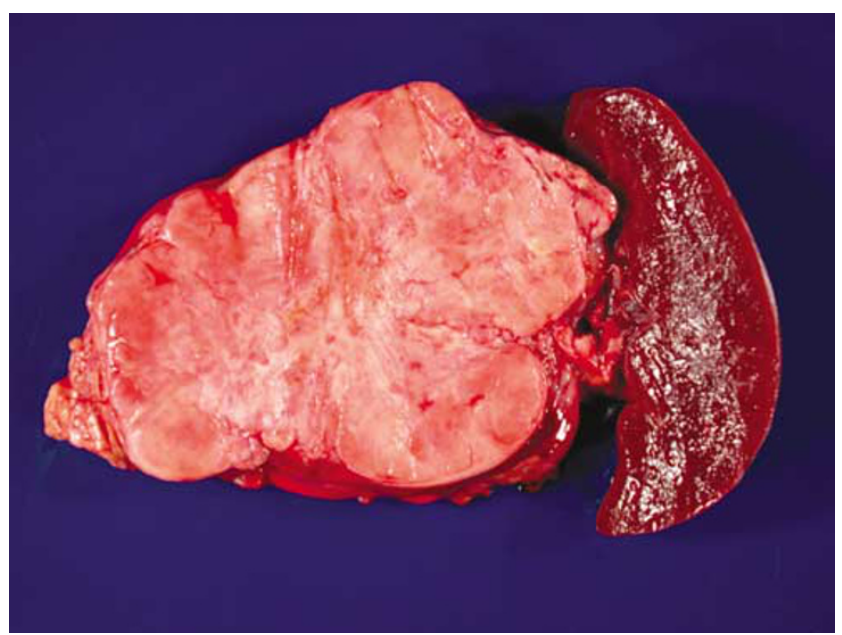

Figure 2 Well-differentiated pancreatic endocrine neoplasm. Grossly, the tumor is multinodular and circumscribed and consists of uniform pink-tan tissue.
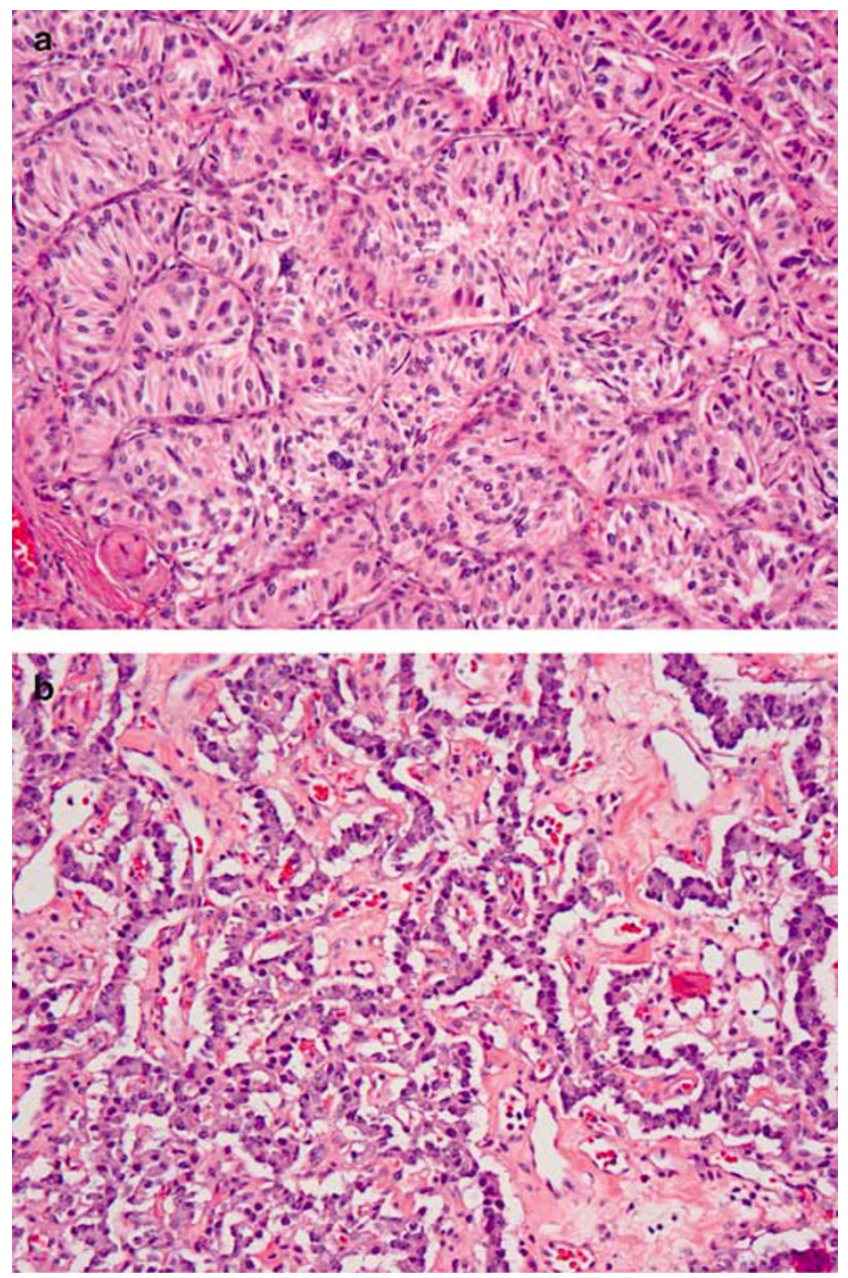

Figure 3 Pancreatic endocrine neoplasm. Microscopically the tumors have typical organoid growth patterns, such as nesting (a) and gyriform (b).

polygonal and vary in size. The cytoplasm may be eosinophilic or amphophilic and is usually moderately abundant. Often the nucleus is peripherally 
located, resulting in a plasmacytoid appearance to the cytoplasm. Lumen formation may occur, usually within large nests of cells, resulting in a cribriform pattern (Figure 4). The cells lining the lumina are cytologically the same as the endocrine cells in the solid regions; this circumstance is to be distinguished from PENs that contain a separate nonendocrine glandular component (see below). Nuclei are round to oval and usually uniform in size and shape, with the classic coarsely stippled 'salt and pepper' chromatin characteristic of other welldifferentiated endocrine neoplasms (Figure 5). Nucleoli are usually inconspicuous, but some PENs have prominent nucleoli. The mitotic rate varies from undetectable $(<1$ mitosis per $50 \mathrm{hpf}$ ) to 10 mitoses per $10 \mathrm{hpf}$; endocrine neoplasms with more than 10 mitoses per $10 \mathrm{hpf}$ are considered poorly differentiated endocrine carcinomas. Necrosis is not typically found in smaller PENs. When present, foci of necrosis may be large and confluent ('infarct-like')

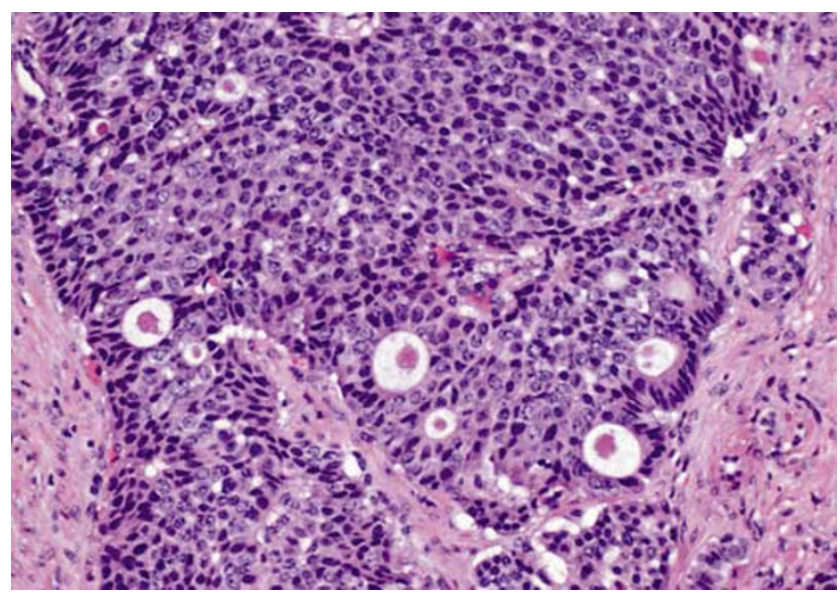

Figure 4 Pancreatic endocrine neoplasm with gland formation. The lumina are lined by endocrine cells.

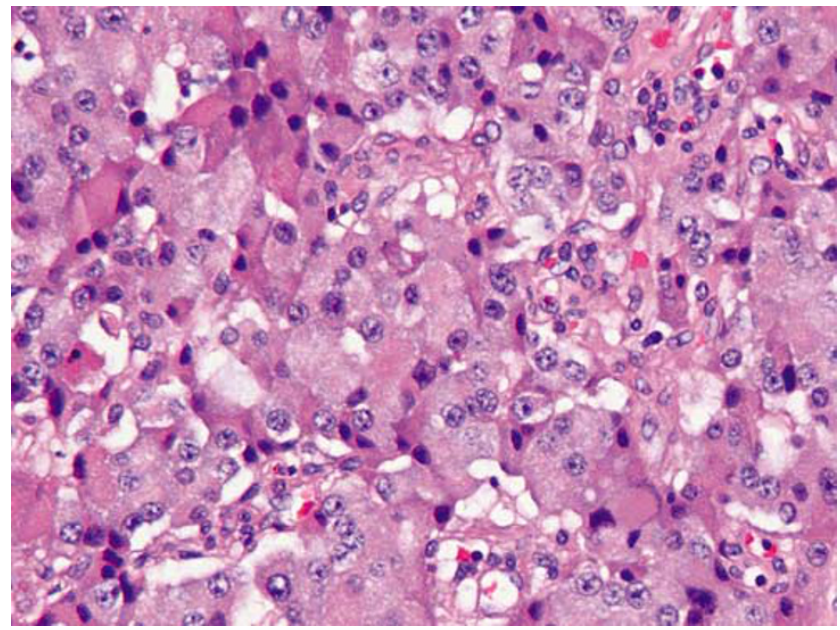

Figure 5 Pancreatic endocrine neoplasm, cytology. The nuclei are uniform with a coarsely stippled chromatin pattern. Mitoses are not evident. or they may appear as more punctate foci in the center of the neoplastic nests.

Many morphologic variants of PENs have been described. Approximately $7 \%$ of PENs are oncocytic. ${ }^{26}$ Oncocytic PENs are architecturally similar to conventional PENs but are composed of cells with abundant granular eosinophilic cytoplasm (Figure 6). ${ }^{26-29}$ Clear cell change also occurs in PENs and is particularly common in PENs arising in patients with VHL syndrome. ${ }^{22}$ In these cases, the cells have abundant foamy cytoplasm (Figure 7), and intracellular fat can be demonstrated. Some PENs have marked nuclear atypia throughout the neoplasm. These 'pleomorphic PENs' may be mistaken for high-grade neoplasms such as ductal carcinomas or undifferentiated carcinomas, ${ }^{30}$ but they do not demonstrate an elevated mitotic rate or necrosis. Despite their atypical cytology, pleomorphic PENs do not appear to have a more aggressive behavior than conventional PENs. Also reported is a variant

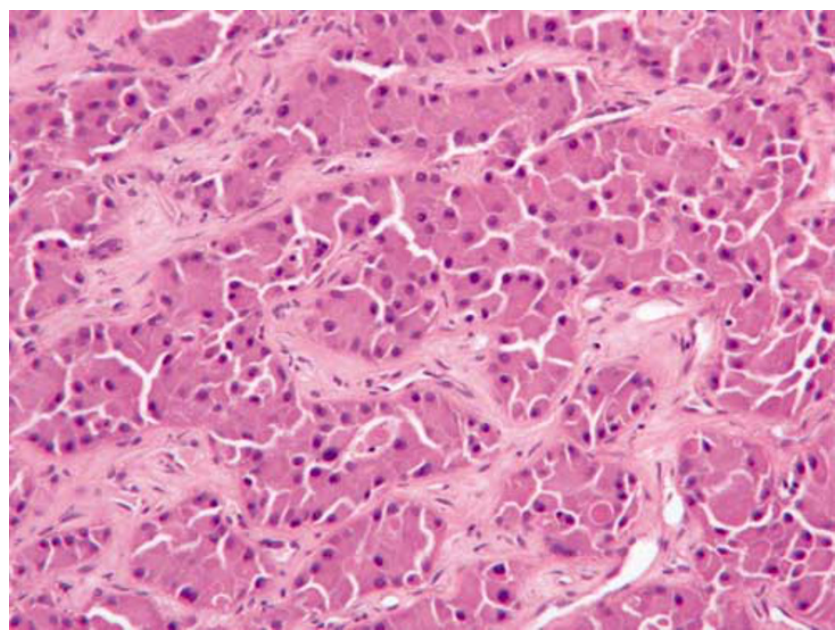

Figure 6 Oncocytic pancreatic endocrine neoplasm. There is abundant granular eosinophilic cytoplasm.

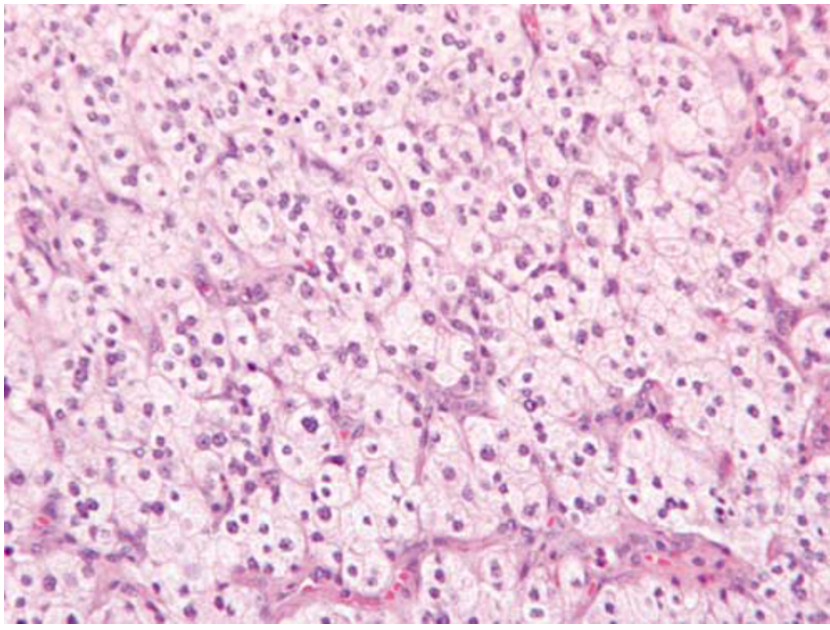

Figure 7 Clear cell pancreatic endocrine neoplasm. The cells have foamy clear cytoplasm. 
S98

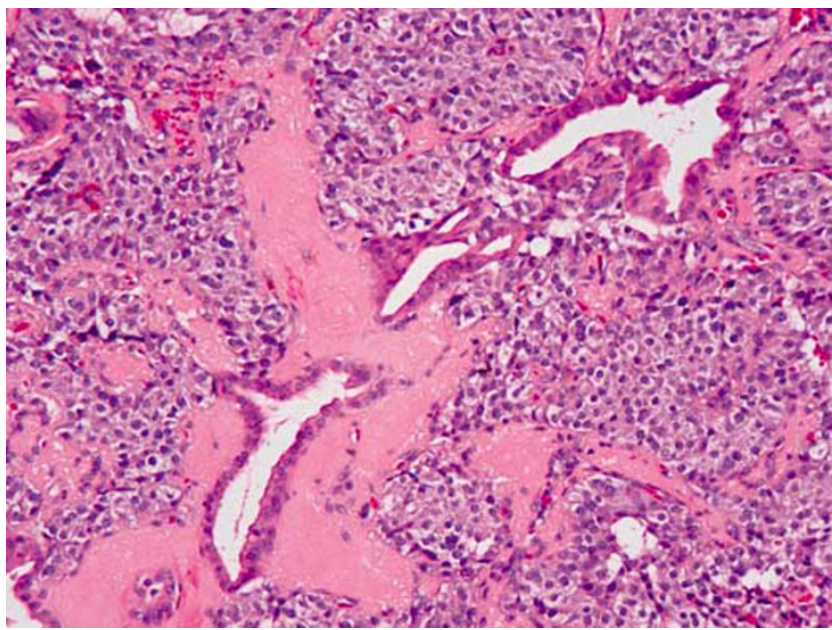

Figure 8 Pancreatic endocrine neoplasm with entrapped nonneoplastic ductules. The glands are cytologically distinct from the surrounding neoplastic endocrine cells.

of PEN with rhabdoid morphology. These neoplasms have eccentrically located nuclei and inclusion-like, glassy cytoplasm.

Although it is common to find focal lumen formation in PENs, some PENs also contain a population of glands that are distinct from the surrounding endocrine elements (Figure 8). The glands resemble small intralobular ducts, and PENs with significant numbers of small glands have been designated 'ductuloinsular tumors' of the pancreas. Although this designation suggests that the glands are an inherent, neoplastic component of the tumor, ${ }^{31,32}$ recent studies have demonstrated that the glands are not monoclonal and are therefore entrapped, non-neoplastic ductules. ${ }^{33}$

By immunohistochemistry, more than $95 \%$ of PENs label for chromogranin and/or synaptophysin, the latter being more consistently expressed. ${ }^{34} \mathrm{CD} 57$ (Leu7), CD 56 (neural cell adhesion molecule), and NSE (neuron-specific enolase) are also usually expressed. Immunohistochemical labeling for specific peptides demonstrates a wide range of positivity. Many different peptides have been detected, ${ }^{10}$ including the normal islet peptides as well as many other ectopic peptides including gastrin, vasoactive intestinal polypeptide, cholecystokinin, adrenocorticotrophic hormone, and others. ${ }^{4}$ The neoplastic cells may also express bioamines such as serotonin. The pattern of labeling for these hormones varies widely; some PENs are diffusely positive for only one peptide, others show focal labeling for one or more peptides. ${ }^{17,35,36}$ Functional PENs usually show labeling for the peptide that is responsible for the clinical syndrome.

PENs also commonly express markers of acinar differentiation (the pancreatic enzymes trypsin or chymotrypsin) in scattered cells. ${ }^{9,37,38}$ If more than $25 \%$ of the neoplastic cells in a predominantly endocrine neoplasm express markers of acinar differentiation, the neoplasm should be classified as a mixed acinar-endocrine carcinoma. ${ }^{39}$ Staining for $\alpha$-1-antitrypsin can also be found in PENs, so this marker is not specific for acinar differentiation. Focal staining for glycoprotein markers of ductal differentiation such as DUPAN2 or CA 19-9 is found in 22 and $13 \%$ of PENs, respectively. ${ }^{9,37,40}$ CEA is much less commonly expressed. It should be noted that immunohistochemical labeling for glycoproteins in a PEN is not sufficient evidence for a diagnosis of mixed ductal-endocrine carcinoma unless a morphologically separate component of ductal adenocarcinoma can be recognized. Normal islet cells express progesterone receptors and CD 99, and about half of PENs label for these markers as well..$^{9,41,42}$ Proliferation markers such as Ki67 are expressed in less than $10 \%$ of the neoplastic cells, and in most cases the rate is between $5 \%$ and less than $1 \% .^{1,4,14,43}$

Genetic studies have identified many chromosomal alterations in PENs; however, activation of oncogenes has not been implicated in their development. Chromosomal losses are more common than gains. ${ }^{44-46}$ Neoplasms arising in patients with the MEN1 syndrome have germ line mutations in the MEN1 gene on chromosome 11q13 and somatic loss of the second allele. Losses on the short arm of chromosome 11 are also present in $70 \%$ of sporadic PENs, but specific MEN1 gene mutations are only present in approximately $20 \%$ of sporadic PENs, suggesting involvement of another tumor suppressor gene on the same chromosomal arm. ${ }^{47-56}$ PENs arising in patients with VHL syndrome usually show biallelic inactivation of the VHL gene, ${ }^{57}$ but this gene is rarely abnormal in sporadic PENs. ${ }^{52}$ Most of the genes involved in the development of ductal adenocarcinoma of the pancreas are not targeted in PENs. ${ }^{49,53,58,59}$ In particular, KRAS, p53, $p 16$, and DPC4 are not mutated in most PENs, although the $p 16$ gene is inactivated by hypermethylation of the promotor in $40 \%$ of PENs. ${ }^{60-62}$ In general, larger and more advanced stage PENs have more genetic alterations than smaller PENs. Thus, there appears to be genetic progression in PENs that parallels clinical progression. In fact, there are data to suggest that PENs begin as small poly- or oligoclonal proliferations and develop into more aggressive monoclonal neoplasms as they grow. ${ }^{63}$

The natural history of PENs has long been regarded to be unpredictable, although a better understanding of prognostic factors now allow relatively accurate prediction of clinical behavior. Small PENs lacking adverse prognostic features (see below) can be cured by surgical resection. Many insulinomas fit this category, as they are generally less than $2 \mathrm{~cm}$ when detected. As insulinomas comprise nearly half of functional PENs, the prognosis of the entire group of functional PENs is better than that of nonfunctional PENs. Most PENs other than the insulinomas are usually larger at diagnosis, and the prognosis for this group is much less favorable. ${ }^{64}$ Approximately $50-80 \%$ of these 
neoplasms recur or metastasize, ${ }^{18,65-68}$ although sometimes only after many years. The 5-year survival after surgical resection for nonfunctional PENs is $65 \%$, and the 10-year survival is $45 \%{ }^{9}$ Additional patients present with metastatic disease and do not undergo resection, so the survival of all patients with PENs is even less than these figures suggest.

One of the most controversial aspects of PENs has been the prediction of prognosis. A number of adverse prognostic factors have been described and are generally well accepted, including tumor size, mitotic rate, presence of necrosis, extrapancreatic invasion, and vascular invasion, in addition to the presence of nodal or distant metastases. ${ }^{1,2,4,9,69}$ Peptide production detected in the serum or by immunohistochemistry is not a prognostic factor for nonfunctional PENs. ${ }^{9}$ Nuclear pleomorphism is also not a useful predictor, ${ }^{30}$ although some studies have demonstrated a correlation between overall nuclear grade and prognosis. ${ }^{9}$ Other factors reportedly predictive of more aggressive behavior (at least in univariate analyses) include loss of progesterone receptor expression, ${ }^{42,43}$ aneuploidy, ${ }^{70,71}$ increased Ki67 labeling index, ${ }^{43,72}$ loss of heterozygosity (LOH) of chromosome $17 \mathrm{p} 13,{ }^{20} \mathrm{LOH}$ of chromosome $22 \mathrm{q},{ }^{73}$ increased fractional allelic loss ${ }^{74}$ upregulated CD44 isoform expression, ${ }^{75,76}$ and immunohistochemical expression of cytokeratin $19 .{ }^{77}$ A number of grading schemes have been proposed for PENs, including some that attempt to separate them into benign and malignant groups as well as others that simply stratify the risk for recurrence. The most recent WHO classification ${ }^{1}$ separates PENs (other than microadenomas) into two general groups: 'welldifferentiated endocrine tumors' and 'well-differentiated endocrine carcinomas'. According to this system, well-differentiated endocrine tumors are confined to the pancreas (or have only local extension into peripancreatic tissues) whereas well-differentiated endocrine carcinomas have either gross local invasion or metastases to lymph nodes or distant sites. Within the well-differentiated endocrine tumor category, those PENs that measure less than $2 \mathrm{~cm}$ in diameter, have less than two mitoses per $10 \mathrm{hpf}$ (or have a Ki67 labeling index less than $2 \%$ ), and demonstrate no perineural or vascular invasion are predicted to have 'benign behavior'; those that either are greater than $2 \mathrm{~cm}$ in diameter, have 2-10 mitoses per $10 \mathrm{hpf}$ (or have a Ki67 index greater than $2 \%$ ), or have perineural or vascular invasion are considered to have 'uncertain behavior'. ${ }^{1}$ No group of PENs other than microadenomas is specifically designated as a benign neoplasm, and the subcategories provide an indication of the likely clinical behavior based on relatively well-characterized prognostic factors. Another recently proposed grading system for PENs utilizes the strong prognostic correlation of proliferative rate and necrosis to separate PENs into low-grade and intermediate-grade categories. ${ }^{9}$ In this classification, low-grade PENs have no necrosis and less than two mitoses per $50 \mathrm{hpf}$ whereas intermediate-grade PENs have either necrosis OR a mitotic rate of $2-50$ per $50 \mathrm{hpf}$. Again, no group of PENs is classified as benign, but the low- and intermediate-grade groups have highly significant differences in disease-free and disease-specific survival.

The differential diagnosis of PENs includes other solid, cellular pancreatic neoplasms that are discussed elsewhere in this review, including acinar cell carcinoma, pancreatoblastoma, mixed acinarendocrine carcinoma, and solid-pseudopapillary neoplasm. Acinar cell carcinoma, pancreatoblastoma, and mixed acinar-endocrine carcinoma are all predominantly acinar neoplasms. ${ }^{39,78-80}$ Recognition of acinar formations is therefore helpful to suggest these entities should be considered. Acinar neoplasms often have single prominent nucleoli and may have an elevated mitotic rate, pancreatoblastomas generally affect young children and have distinctive squamoid nests. ${ }^{81}$ If any of these acinar neoplasms is considered, immunohistochemical staining for pancreatic enzymes (trypsin, chymotrypsin, and lipase) can be used to document the acinar differentiation. . $^{39,78,79}$ Solid-pseudopapillary neoplasm shares some architectural features with PENs but additionally has characteristic degenerative pseudopapillae in additional to aggregates of foamy histiocytes, large cytoplasmic hyaline globules, and longitudinal nuclear grooves. ${ }^{82}$ Although PENs and solid-pseudopapillary neoplasms both express synaptophysin and CD 56, solid-pseudopapillary neoplasms are never chromogranin positive, express CD 10, and show an abnormal nuclear pattern of labeling for $\beta$-catenin. ${ }^{83}$ When PENs display variations in nuclear morphology and gland formation, they may be mistaken for ductal adenocarcinomas. In contrast to ductal adenocarcinomas, PENs generally maintain some degree of pushing growth pattern (at least grossly), and they usually lack significant mitotic activity and necrosis. Careful attention to the cytologic appearance as well as recognition of the wide array of patterns encountered in PENs will aid in proper diagnosis. Immunolabeling for chromogranin and synaptophysin is usually diagnostic if the possibility of a PEN is considered.

The least common endocrine neoplasm to arise in the pancreas is poorly differentiated (high grade) endocrine carcinoma. These neoplasms are highly aggressive, poorly differentiated carcinomas with morphologic features suggesting endocrine differentiation, a high proliferative rate (greater than 10 mitoses per $10 \mathrm{hpf}$ ), and abundant necrosis. Poorly differentiated endocrine carcinomas constitute at most $2-3 \%$ of all pancreatic endocrine neoplasms. ${ }^{4}$ They usually arise in adults ${ }^{84}$ and there is a male predominance. ${ }^{85}$ Some cases have associated paraneoplastic syndromes including Cushing's syndrome, ${ }^{86}$ hypercalcemia, ${ }^{87}$ and carcinoid syndrome. ${ }^{16}$ In contrast to well-differentiated 
PENs, poorly differentiated endocrine carcinomas are highly aggressive, with early dissemination and a rapidly fatal course. Some examples have the typical pathologic features of small cell carcinomas $^{85,88,89}$ and are designated as such. Other poorly differentiated endocrine carcinomas are composed of larger cells with more abundant cytoplasm, resembling large cell neuroendocrine carcinomas of the lung and other sites. The mitotic rate is high in both the small cell and large cell type of poorly differentiated endocrine carcinoma (Figure 9), averaging $30-40$ per $10 \mathrm{hpf}$ in large cell endocrine carcinomas and 50-80 per $10 \mathrm{hpf}$ in small cell carcinomas. Immunohistochemistry reveals positivity for synaptophysin and chromogranin in most poorly differentiated endocrine carcinomas of the pancreas, although the labeling may be focal. For histologically typical examples of small cell carcinoma, it is not required to document endocrine differentiation to establish the diagnosis, but for the large cell type, positivity for one of these markers should be found. Reflecting the high mitotic rate, Ki67 stains $40-90 \%$ of the cells in poorly differentiated endocrine carcinomas. Owing to the rarity of poorly differentiated endocrine carcinomas in the pancreas, the possibility of a metastasis from the lung or direct extension from a contiguous site (eg, the ampulla of Vater, where poorly differentiated endocrine carcinomas are more common ${ }^{90}$ ) must always be considered. Pancreatic involvement by primitive neuroectodermal tumors ${ }^{91}$ and desmoplastic small round cell tumors ${ }^{92}$ should also be considered in the differential diagnosis.

\section{Acinar cell carcinoma and mixed acinar carcinomas}

Acinar differentiation in neoplasms is defined as the production of pancreatic enzymes, packaged in zymogen granules, by the neoplastic cells. ${ }^{93}$ Despite the fact that acinar cells make up the bulk of the pancreas, pancreatic neoplasms exhibiting acinar

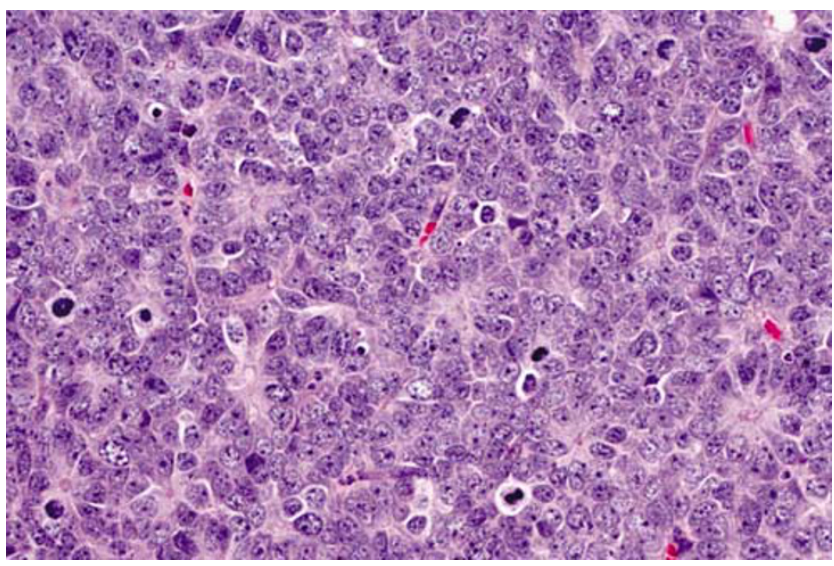

Figure 9 Poorly differentiated endocrine carcinoma. There are abundant mitotic figures. differentiation are rare. Most acinar neoplasms are malignant (acinar cell carcinomas or variants thereof); solid acinar adenomas are not well-recognized, although recently benign acinar cell cystadenomas have been reported. ${ }^{94-96}$

Approximately $1-2 \%$ of adult pancreatic neoplasms and $15 \%$ of pediatric neoplasms are acinar cell carcinomas. $^{78,97,98}$ The adult patients average 58 years old, and males are more commonly affected. ${ }^{78,97,98}$ Presenting symptoms are usually nonspecific (abdominal pain, nausea, vomiting, and weight loss) and jaundice is rare. ${ }^{78,97-99}$ Some patients (10-15\%) develop the lipase hypersecretion syndrome, in which massive serum lipase elevations are accompanied by subcutaneous fat necrosis and polyarthralgia. ${ }^{100-104}$ In most cases, hepatic metastasis are present at the time the syndrome develops. A number of reports have also documented secretion of alpha-fetoprotein (AFP), especially in younger patients. ${ }^{105-109}$

Acinar cell carcinomas may arise in any portion of the pancreas. ${ }^{78,97,98}$ Most are large, averaging $10 \mathrm{~cm}$ in diameter, and circumscribed. They are usually tan to red, soft and fleshy (Figure 10). The low-power microscopic appearance is characterized by high neoplastic cellularity and a paucity of fibrous stroma (Figure 11). The periphery of the carcinoma may appear circumscribed, although invasion of tumor through the capsule is common. Several different architectural patterns are found, the most common being the solid and acinar patterns (Figure 12); a mixture of patterns is often found within an individual tumor. In the acinar pattern, the neoplastic cells form minute lumina, the nuclei are basally located, and there is a moderate

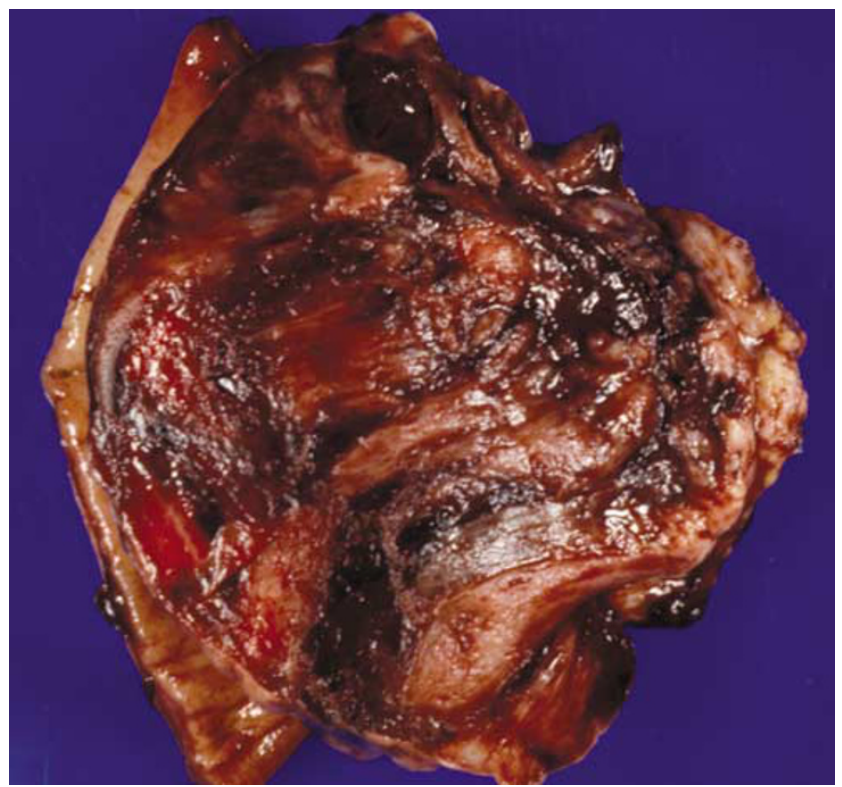

Figure 10 Acinar cell carcinoma. Grossly, the tumor is soft and circumscribed, with abundant hemorrhage. It forms a polypoid mass projecting into the duodenum. 


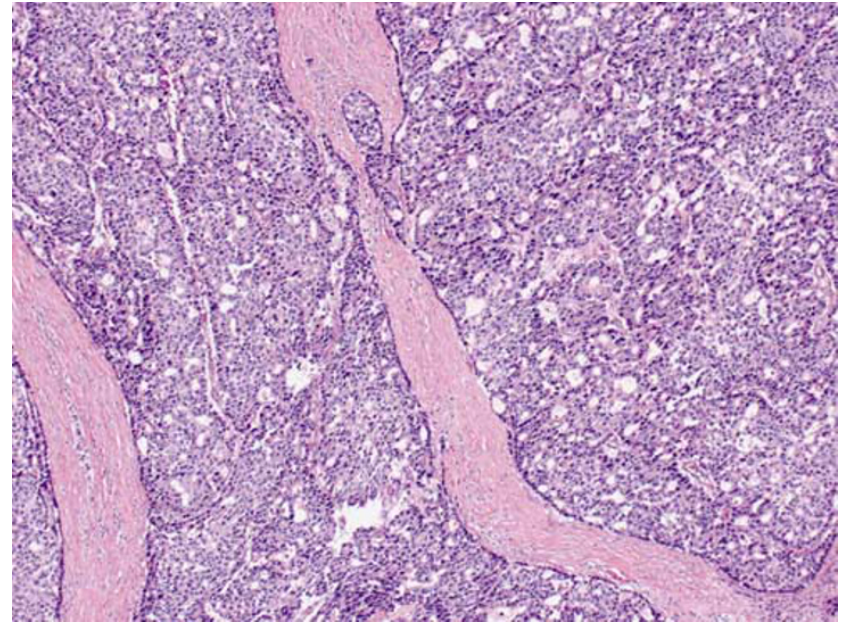

Figure 11 Acinar cell carcinoma. At low power the tumor is arranged in highly cellular lobules separated by bands of collagenized stroma.
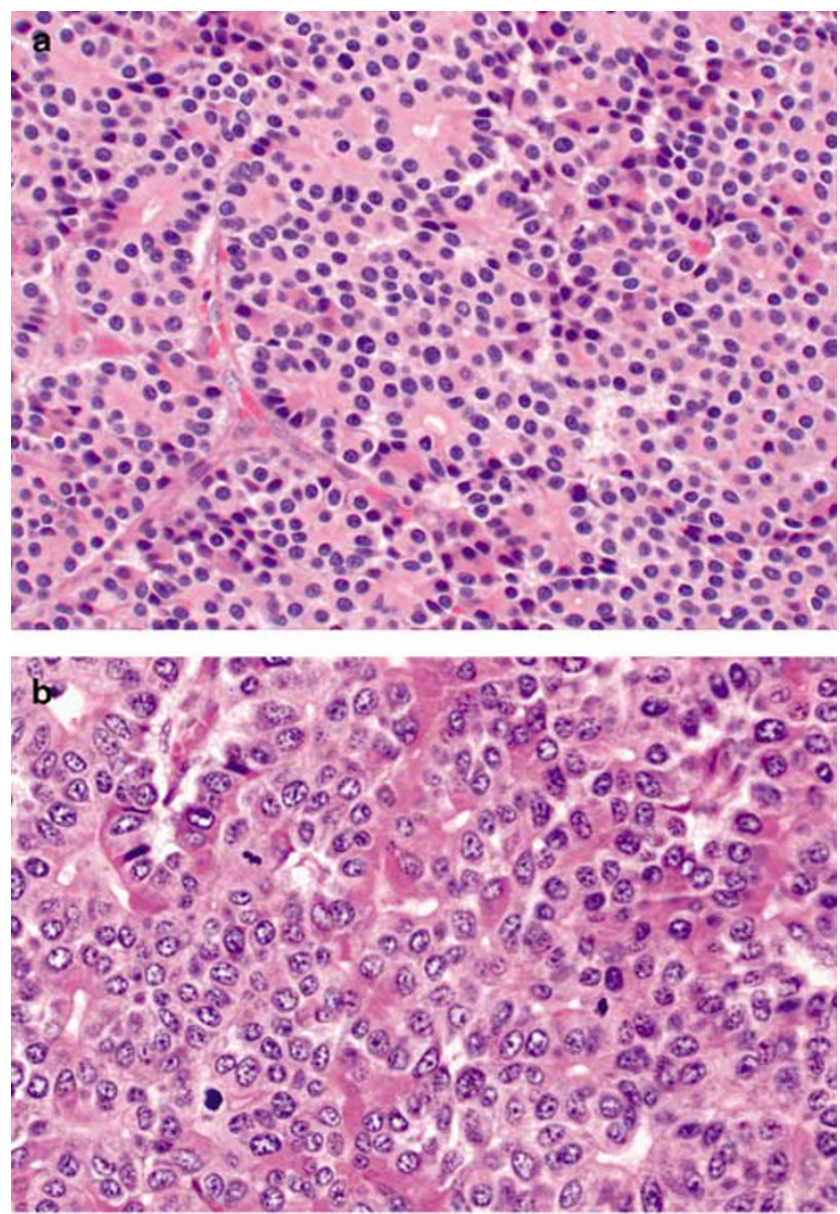

Figure 12 Acinar cell carcinoma. The typical architectural patterns are acinar (a) and solid (b). The cells have moderate amounts of granular, eosinophilic cytoplasm.

amount of eosinophilic granular apical cytoplasm. The solid pattern is characterized by sheets and nests of cells without evident lumen formation.

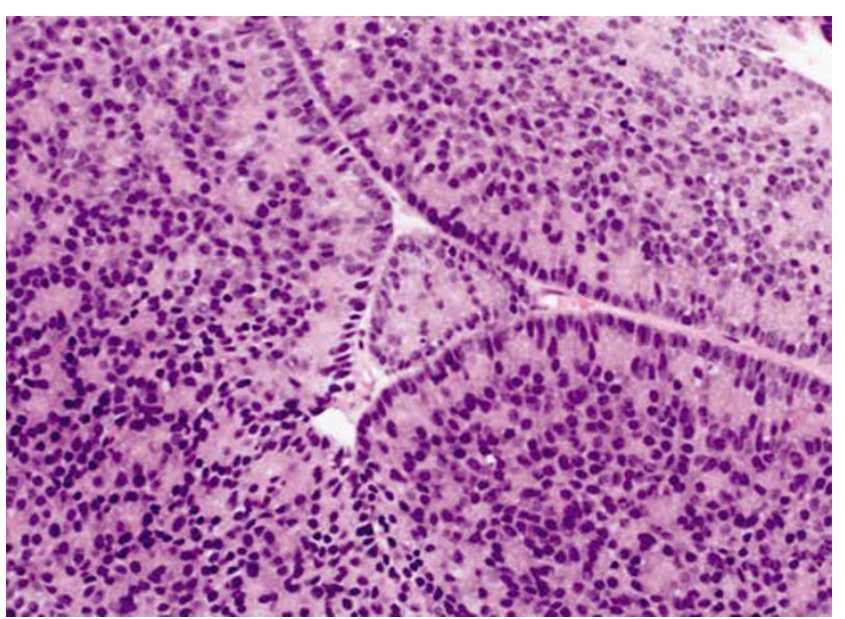

Figure 13 Acinar cell carcinoma. The nuclei are uniform and well polarized, with basal palisading at the interface with the stroma.

Basal palisading of the nuclei may be found at the interface of the solid nests with the stroma (Figure 13). Less common architectural patterns include a glandular pattern, in which acinar structures are dilated, and a trabecular pattern. The nuclei in acinar cell carcinomas are relatively uniform, generally with only moderate variability in shape and size. Large, central, single nucleoli are characteristic and can provide an important clue to the diagnosis in cases with a solid growth pattern. The mitotic rate is variable; but most acinar cell carcinomas have easily detectable mitoses. The cytoplasm in acinar cell carcinomas with abundant zymogen granules is strikingly eosinophilic and finely granular (Figure 12). In many cases, however, the cytoplasmic granularity is not so well developed, and special stains are needed to demonstrate the presence of enzyme production. A rare variant of acinar cell carcinoma (acinar cell cystadenocarcinoma) is composed of innumerable variably-sized cysts, each lined by neoplastic acinar cells. ${ }^{98,110-112}$

Zymogen granules are positive for periodic acidSchiff (PAS), resistant to diastase digestion (dPAS) in $95 \%$ of acinar cell carcinomas. In cases with typical histologic features, the finding of granular dPAS positivity in the apical cytoplasm may be sufficient to confirm the diagnosis; however, many acinar cell carcinomas do not contain sufficient quantities of zymogen granules for this stain to provide convincing results, and immunohistochemical staining is a much more specific and sensitive technique. Staining for enzymes, especially trypsin and chymotrypsin, has a $95 \%$ sensitivity to detect acinar differentiation (Figure 14).4,78,98,113,114 Interestingly, pancreatic amylase is rarely detected in acinar cell carcinomas. ${ }^{78,98}$ Acinar cell carcinomas also commonly have focal endocrine differentiation. ${ }^{78,98,115}$ Scattered cells that stain for chromogranin or synaptophysin are found in $35-54 \%$ of cases. Carcinomas with greater degrees of endocrine differentiation ( $>25 \%$ of the neoplastic cells) are 
S102

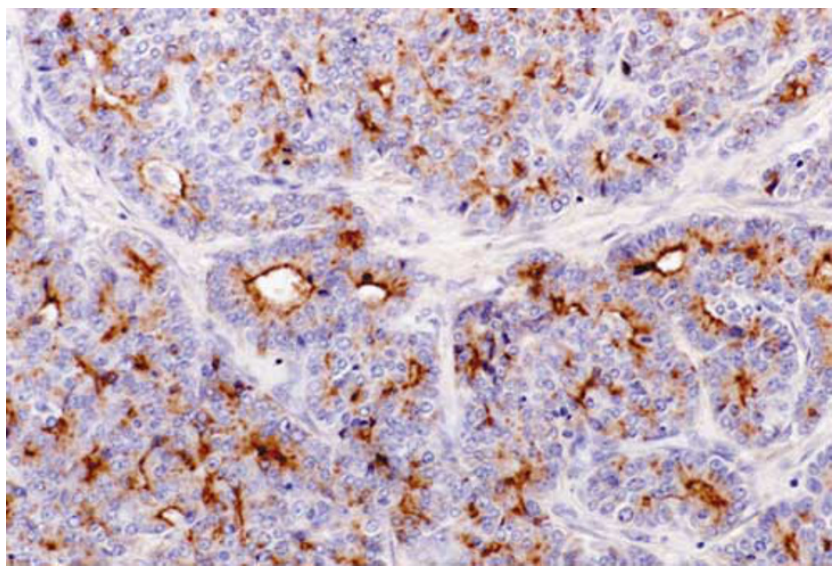

Figure 14 Acinar cell carcinoma. Immunohistochemical staining for trypsin.

classified as mixed acinar-endocrine carcinomas (see below). AFP has been detected by immunohistochemistry in acinar cell carcinomas in patients with and without elevated serum AFP. ${ }^{105-108,116}$

Ultrastructural examination of acinar cell carcinomas ${ }^{78,117-122}$ reveals abundant rough endoplasmic reticulum and mitochondria. The cells rest on a basement membrane and have well-developed lumina. Most acinar cell carcinomas contain large (125-1000 nm) electron dense zymogen granules. A second granule type, the irregular fibrillary granule, is also highly characteristic of pancreatic acinar differentiation. ${ }^{78,118,119,121}$ These granules are generally larger than the round zymogen granules, ranging up to $3500 \mathrm{~nm}$, and are irregularly shaped, often elongated, angulated or bilobed, with fibrillary internal contents.

Acinar cell carcinomas generally lack the most common abnormalities of ductal carcinomas, ${ }^{123,124}$ such as mutations in the KRAS oncogene $\mathrm{e}^{53,59,98,125}$ or abnormalities in p53, DPC4, and p16. ${ }^{53,126}$ Recent work has identified losses on chromosome arm $11 \mathrm{p}$ in $50 \%$ of cases. ${ }^{126}$ In addition, $24 \%$ of acinar cell carcinomas have abnormalities in the APC/ $\beta$-catenin pathway, either through activating mutations of the $\beta$-catenin gene or truncating mutations of the $A P C$ gene. ${ }^{126}$

Acinar cell carcinomas are highly aggressive neoplasms. Approximately $50 \%$ of patients have metastatic disease at presentation, and more than half of the remaining patients develop metastases later in their clinical course ${ }^{78}$ Most often metastatic disease is found in regional lymph nodes and the liver. The ultimate survival of patients with acinar cell carcinoma is very poor (5-year survival $=6 \%),{ }^{78}$ although it appears that this neoplasm is not quite as rapidly lethal as conventional ductal adenocarcinoma. The median survival for all patients is 18-19 months, ${ }^{78,127}$ and it is not uncommon for patients with distant metastases to survive for 2-3 years. Pediatric patients seem to have a better prognosis than adults. ${ }^{78}$
The differential diagnosis of acinar cell carcinoma is similar to that of PENs (see above), with which acinar cell carcinomas are commonly confused. Because acinar cell carcinomas can contain scattered endocrine cells, the finding of only focal immunolabeling for chromogranin or synaptophysin in a putative PEN is not sufficient to exclude the diagnosis of acinar cell carcinoma. Immunohistochemical staining for trypsin and chymotrypsin is needed to assess for acinar differentiation in such cases. Furthermore, the quantitation of acinar and endocrine components (if present) is necessary to recognize mixed acinar-endocrine carcinomas (see below). Pancreatoblastomas are also fundamentally acinar neoplasms with similar histology features as well as prominent acinar differentiation based on immunohistochemistry. However, pancreatoblastomas usually affect children under 10 years old, and microscopically they have characteristic squamoid nests that distinguish them from acinar cell carcinomas. A final entity that may be confused with acinar cell carcinoma is solid-pseudopapillary neoplasm. ${ }^{82}$ These neoplasms can have extensive solid areas with uniform, polygonal cells resembling the solid areas of acinar cell carcinoma. However, solidpseudopapillary neoplasms demonstrate characteristic degenerative pseudopapillary formations and never exhibit true lumen formation, so the presence of an acinar or glandular pattern would exclude this entity. Finally, solid-pseudopapillary neoplasms never express trypsin or chymotrypsin, instead staining for $\alpha$-1-antitrypsin, vimentin, CD56, and CD10.

Some pancreatic neoplasms have significant elements of more than one line of differentiation, and although tumors with all possible combinations of cell types have been reported (mixed acinar-endocrine carcinoma, mixed acinar-ductal carcinoma, mixed ductal-endocrine carcinoma, and mixed acinar-endocrine-ductal carcinoma), most of these mixed neoplasms have a predominant acinar component. Mixed acinar-endocrine carcinoma is the best characterized of these. ${ }^{99,109,115,120,128-133}$ By arbitrary definition, each component must comprise at least $25 \%$ of the neoplasm for a diagnosis of mixed acinar-endocrine carcinoma. In most cases, the histological features only hint at the possibility of bidirectional differentiation, and only by immunohistochemistry can the presence and extent of the two cell types be determined. Other mixed tumors are defined similarly, with the mixed acinar-ductal and mixed acinar-endocrine-ductal carcinomas having elements of ductal differentiation in the form of intracellular mucin-containing cells or cells that stain for glycoproteins such as CEA, CA 19-9, B72.3, DUPAN2, or CA 125. Again, $25 \%$ of the tumor must be composed of each cell type for the diagnosis to be established. All of these mixed acinar carcinomas are clinically aggressive, similar to pure acinar cell carcinomas. 


\section{Pancreatoblastoma}

Pancreatoblastoma is a malignant epithelial neoplasm showing multiple lines of differentiation, most prominently acinar, that grows in solid, nesting, and acinar patterns and has characteristic squamoid nests. ${ }^{4,134,135}$ Pancreatoblastoma is the most common pancreatic neoplasm of childhood, ${ }^{136,137}$ where it makes up approximately $25 \%$ of the cases. ${ }^{136-138}$ Most pancreatoblastomas occur in children under 10 (mean age of pediatric cases is 4 years), although one-third of reported cases have affected adults. ${ }^{79,139-146}$ There is a slight male predominance. Some pancreatoblastomas have occurred in patients with Beckwith-Weidemann syndrome, and these cases were congenital and cystic. ${ }^{147-150}$ A single case was reported in an adult patient with Familial Adenomatous Polyposis. ${ }^{151}$ Presenting symptoms are usually nonspecific; jaundice is uncommon, and the paraneoplastic syndromes of PENs and acinar cell carcinoma have not been reported. ${ }^{79,139-143,145,146}$ Like acinar cell carcinomas, pancreatoblastomas can have serum elevations in AFP. ${ }^{142,143,152-157}$

Pancreatoblastomas average $10.6 \mathrm{~cm}$ and arise in the head and the tail of the gland with equal frequencies..$^{79,139-143,145,146}$ Pancreatoblastomas are usually well-circumscribed and lobulated, soft, and fleshy on cut section. Microscopically, at low power the tumor has large lobules of highly cellular tissue separated by broad fibrous bands (Figure 15). The lobules often have a geographic pattern of lighter and darker staining cells, reflecting the different cell types of pancreatoblastoma. The darker cells are sheets and nests of relatively small epithelial cells, some of which form acinar lumina. The nuclei are small and round with prominent central nucleoli. The cytoplasm is usually scant and amphophilic, although some cells may have

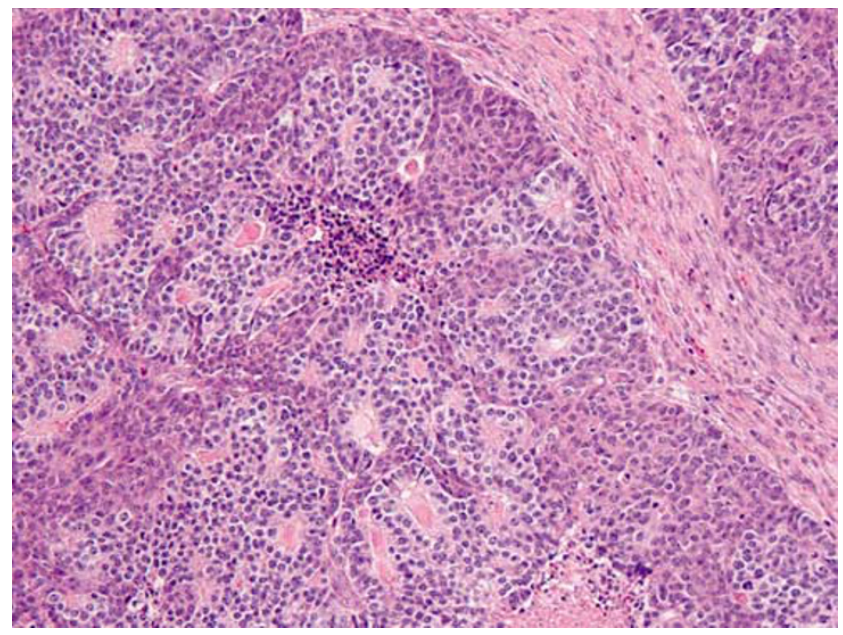

Figure 15 Pancreatoblastoma. At low power the tumor is lobulated and has a geographic pattern owing to the different cell types that are present. The stroma is hypercellular. granular eosinophilic cytoplasm. The lighter cells are usually arranged in nests that can be circumscribed. These cells have more abundant eosinophilic cytoplasm and the nuclei are larger, more oval, and have more pale-staining chromatin than those in the darker staining regions. Some of the lighter cells are spindle shaped, and the whorling pattern of these nests produces a somewhat squamous appearance (Figure 16). Rarely, keratinization is found as well. These clusters of cells have been designated 'squamoid nests' (or squamoid corpuscles) and are one of the most characteristic features of pancreatoblastomas. Some pancreatoblastomas also have mucinous glands, but these are rare. Finally, the stromal bands between the epithelial islands are composed of hypercellular spindle cells with variable collagenization. The stroma is particularly cellular in pancreatoblastomas affecting children, and in rare cases a neoplastic mesenchymal component is present. ${ }^{79}$

Immunohistochemical staining demonstrates the multiple epithelial lines of differentiation that characterize pancreatoblastomas. Many cases show labeling for markers of acinar, endocrine, and ductal differentiation, although in almost every case, acinar differentiation is predominant. Positive staining for trypsin and chymotrypsin is found in nearly every case; lipase is positive less commonly. ${ }^{79,158-161}$ Endocrine markers chromogranin and synaptophysin are positive in two-thirds of cases in a highly variable proportion of the cells. ${ }^{79}$ Staining for islet peptides is not generally found. Finally, the ductal elements, present in 50-65\% of cases, express glycoprotein markers such as CEA, B72.3, and DUPAN-2. ${ }^{79,159}$ Interesting, the squamoid nests do not demonstrate a consistent direction of differentiation based on immunohistochemistry. In most cases the squamoid nests are not immunoreactive, although they may occasionally label with acinar or

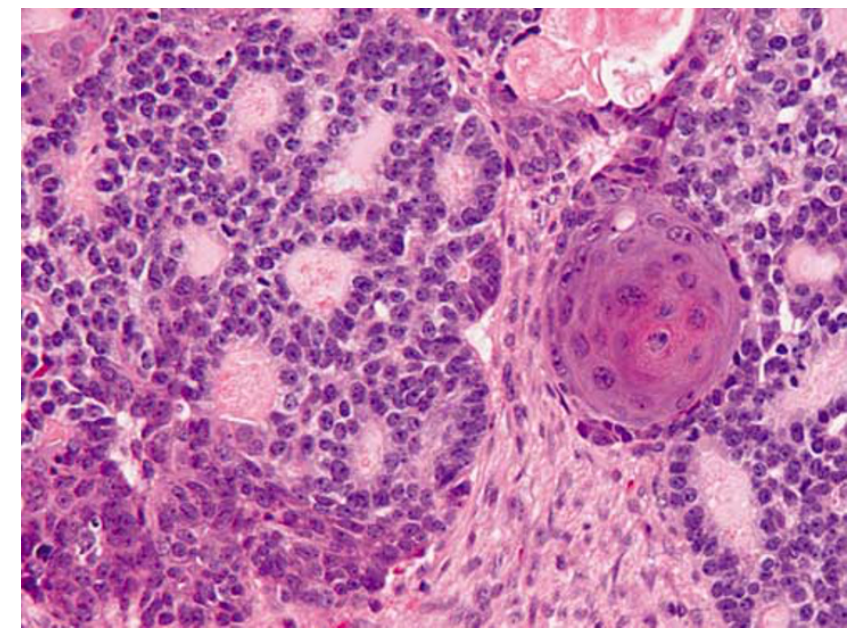

Figure 16 Pancreatoblastoma. The tumor has well-developed acinar formations and contains circumscribed squamous nests (right), a helpful diagnostic feature. 
endocrine markers, and in $30 \%$ of the cases they label with antibodies to carcinoembryonic antigen. ${ }^{79}$ AFP is expressed in some pancreatoblastomas, typically those with serum elevations. ${ }^{142,143,152-157}$

Ultrastructural examination of pancreatoblastomas confirms the presence of acinar differentiation, with zymogen granules and irregular fibrillary granules that are somewhat less abundant than in acinar cell carcinomas. Some cases also have ultrastructural evidence of endocrine and ductal differentiation (neurosecretory and mucin granules). ${ }^{79,117,143,145,152,159}$

The molecular alterations in pancreatoblastoma are similar to those of hepatoblastoma and acinar cell carcinoma. ${ }^{151}$ The most common genetic alteration identified to date is $\mathrm{LOH}$ of the short arm of chromosome $11 \mathrm{p} .{ }^{148,151}$ Alterations in the $\beta$-catenin/ APC pathway have been reported in $50-80 \%$ of pancreatoblastomas. ${ }^{151,162}$ Most often these involve the $\beta$-catenin gene, although a pancreatoblastoma that arose in a patient with familial adenomatous polyposis had biallelic inactivation of the $A P C$ gene. ${ }^{151}$ Most pancreatoblastomas lack the common genetic alterations of infiltrating ductal adenocarcinoma: The DPC4 gene is targeted in only a minority $(22 \%)$ of cases, ${ }^{151}$ and most pancreatoblastomas are wild type for the KRAS oncogene and show normal expression of p53. ${ }^{79,139,151}$

One-third of patients with pancreatoblastomas have metastases at the time of diagnosis, and additional patients develop metastases later in their course..$^{79,139-146}$ The liver is the most common site of metastases, followed by regional lymph nodes, lung, and peritoneum. ${ }^{79,139-143,145,146}$ The prognosis of pancreatoblastomas differs in children and adults. Pediatric patients with localized tumors can be cured by complete surgical resection. Children with metastatic disease have generally faired poorly, although recent reports of favorable responses to chemotherapy and radiation ${ }^{163-167}$ suggest that even some of these patients may experience long-term survival. In adults, pancreatoblastomas have been nearly universally fatal, with most cases progressing quickly, similar to acinar cell carcinomas. ${ }^{79,144}$

The differential diagnosis includes the other solid, cellular neoplasms of the pancreas discussed herein. However, the extensive acinar differentiation of pancreatoblastomas along with the close histologic similarities of pancreatoblastoma to acinar cell carcinoma (and mixed acinar carcinomas) can make these entities hard to distinguish, especially on the basis of a biopsy. Although many histologic features differ between classic cases of acinar cell carcinoma and pancreatoblastoma (extent of lobulation, cellularity of stroma, geographic lowpower pattern, prominence of endocrine and ductal components, etc), it is the squamoid nests that most specifically distinguish these two neoplasms. Some pancreatoblastomas have only scarce squamoid nests, and it can be argued that pancreatoblastoma and acinar cell carcinoma are so closely related that they could be considered the same entity. But there are clear differences, and we regard the relationship of the two to be similar to that of hepatocellular carcinoma and hepatoblastoma. In pediatric patients, most neoplasms with acinar differentiation prove to be pancreatoblastomas, so a careful search for squamoid nests should be performed in an effort to establish the diagnosis of pancreatoblastoma. In adults, acinar cell carcinomas are more common, and one should reserve the diagnosis of pancreatoblastoma for cases with classic histology features.

\section{Solid-pseudopapillary neoplasm}

Solid-pseudopapillary neoplasm is a distinctive low-grade malignant epithelial neoplasm characterized by a solid growth pattern of discohesive polygonal cells with abundant degenerative changes, including cystic degenerative and formation of pseudopapillae. ${ }^{4,82,135,168}$ The line of cellular differentiation remains uncertain despite numerous studies. Many alternative terms have been applied to solid-pseudopapillary neoplasm, including solid-pseudopapillary tumor, papillary cystic neoplasm, solid and papillary epithelial neoplasm, papillary-cystic epithelial neoplasm, papillarycystic carcinoma, solid and papillary neoplasm, Hamoudi tumor, and Frantz's tumor.

Solid-pseudopapillary neoplasms are uncommon, accounting for $2-5 \%$ of all pancreatic malignancies. $^{4,169,170}$ These tumors predominantly affect females ( $89 \%$ female), with a mean age of 28 years (range of 7-79 years). Most patients present with nonspecific symptoms related to the intra-abdominal mass, ${ }^{169,171-173}$ and a palpable mass or incidental radiographic finding may be the route of tumor discovery in asymptomatic individuals. Rarely solid-pseudopapillary neoplasms rupture, causing potentially life-threatening hemoperitoneum. ${ }^{174-176}$ A number of solid-pseudopapillary neoplasms have been reported in women who are pregnant or postpartum, ${ }^{171,177}$ but it is possible that the tumors are detected at this time as they typically affect women of child-bearing age who come to medical attention at the time of pregnancy.

Solid-pseudopapillary neoplasms may arise anywhere within the pancreas. ${ }^{169,170,173,175,178}$ Most cases are quite large at diagnosis (mean diameter of 9-10 cm), although with the increased use of crosssection imaging techniques, more cases are being diagnosed when less than $5 \mathrm{~cm} .{ }^{179,180}$ Grossly, solidpseudopapillary neoplasms appear to be circumscribed or even partially encapsulated. The larger examples are particularly prone to develop degenerative cystic changes, and near complete cystic change may occur, simulating a pseudocyst. In the solid areas, the tumors are red-tan and very soft, friable, and hemorrhagic (Figure 17). ${ }^{175,180}$ True necrosis is uncommon but may occur. Some 


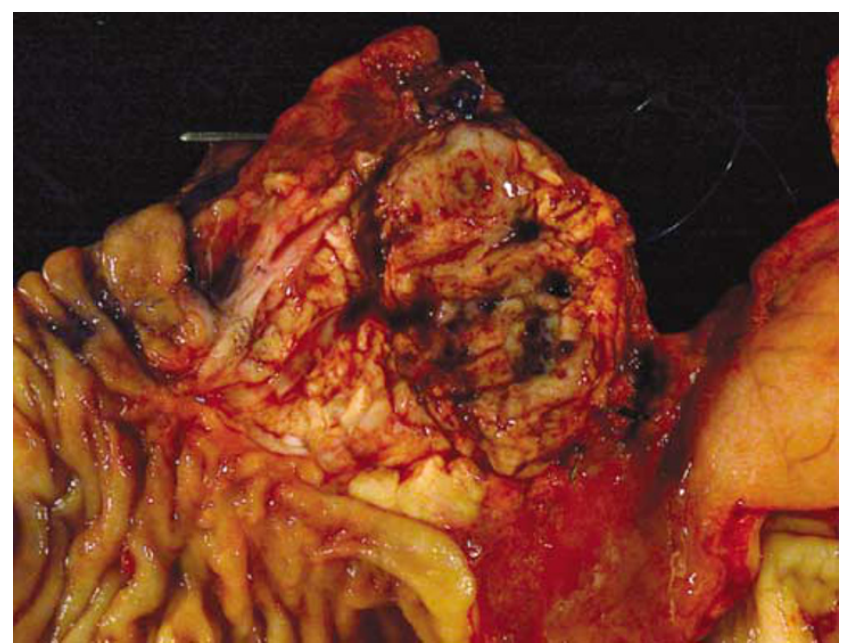

Figure 17 Solid pseudopapillary neoplasm. Grossly the tumor is soft and fleshy, with areas of hemorrhage. Small irregular cysts are present.

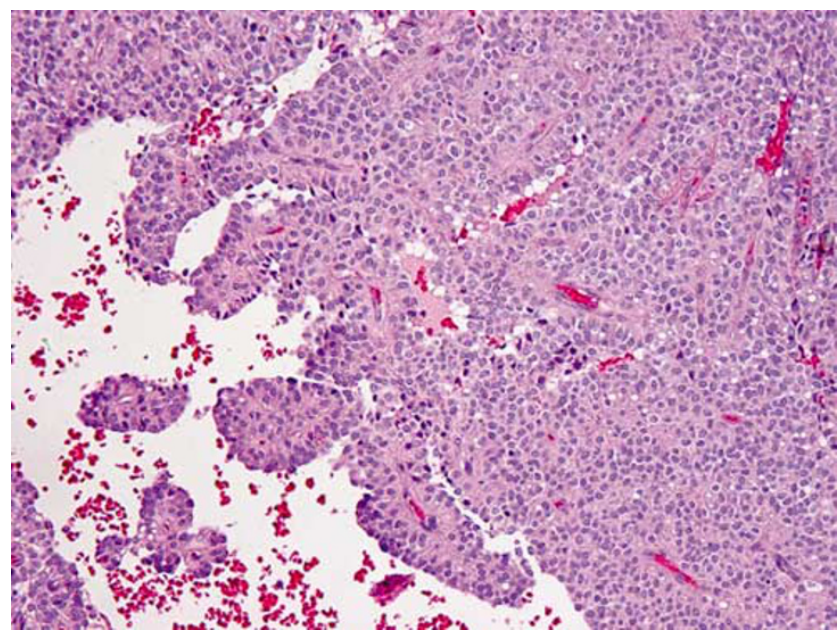

Figure 18 Solid pseudopapillary neoplasm. Solid areas without specific architectural patterns give way to irregular cystic spaces containing pseudopapillae.

examples have more abundant fibrous stroma that imparts a firm consistency.

The microscopic appearance of solid-pseudopapillary neoplasm is somewhat variable but highly characteristic. Solid sheets of uniform polygonal cells are separated into nests by abundant capillarysized vessels (Figure 18). ${ }^{178,179,181,182}$ There is no true lumen formation. The cells are relatively discohesive, and in areas away from the vessels, cell drop away, leaving a ragged cuff of neoplastic cells clinging to the blood vessels; this results in the characteristic pseudopapillae (Figure 19). Other degenerative changes included foamy cytoplasm in the tumor cells as well as aggregates of foamy histiocytes. The nuclei are sometimes oriented away from the vessels, resulting in a zone of cytoplasm separating the capillaries from the nuclei. The cytoplasm is usually eosinophilic but can also be

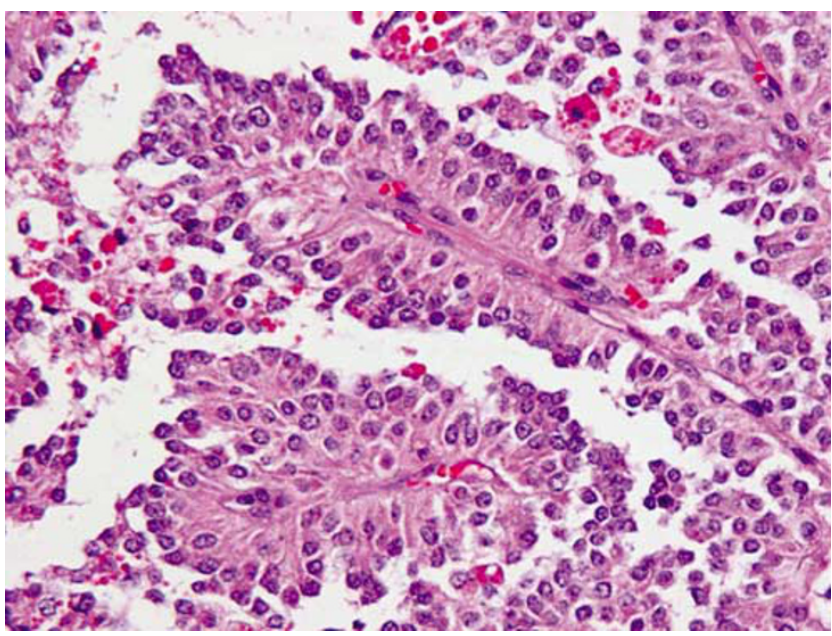

Figure 19 Solid pseudopapillary neoplasm. The pseudopapillae consist of central capillaries surrounded by a cuff of neoplastic cells. The nuclei are oriented away from the vessels.

clear or vacuolated. Clusters of cells contain large eosinophilic dPAS-positive hyaline globules, another characteristic features (Figure 20a). The nuclei are round to oval, uniform, and have frequent longitudinal nuclear grooves (Figure 20b). Mitoses are very rare (range 0-10/50 high-power fields), and pleomorphism is unusual but has been reported. ${ }^{181,183}$ Some cases have more extensive stromal hyalinization, resulting in nests of tumor entrapped within the heavily collagenized stroma. Balls of stroma with myxoid change may be found within the solid regions of the tumor as well.

Despite the well-circumscribed gross appearance, the neoplastic cells often invade the adjacent nonneoplastic pancreas, intimately intermingling with the parenchymal elements. ${ }^{181}$ The adjacent acini often appear separated from the neoplastic cells by only a basement membrane. Another characteristic finding is 'blood lakes' at the periphery of the neoplasm: pools of red cells are found admixed with nests of neoplastic cells, giving the appearance of vascular invasion, although definite penetration of capsular vessels is hard to document in these regions.

Recently, two cases were reported of high-grade malignant transformation in solid-pseudopapillary neoplasm. ${ }^{183}$ These cases showed residual areas of a conventional solid-pseudopapillary neoplasm but also had diffuse sheets of more markedly atypical cells with true tumor necrosis and a relatively high mitotic rate (35 and 69 per $50 \mathrm{hpf}$, respectively). One of these neoplasms contained a focus of sarcomatoid carcinoma as well. These two patients both experienced rapid disease progression and death from tumor, in contrast to the normal natural history of solid-pseudopapillary neoplasm (see below).

Most solid-pseudopapillary neoplasms stain for vimentin, CD10, neuron-specific enolase, CD56, progesterone receptors, and $\alpha$-1-antitrypsin 

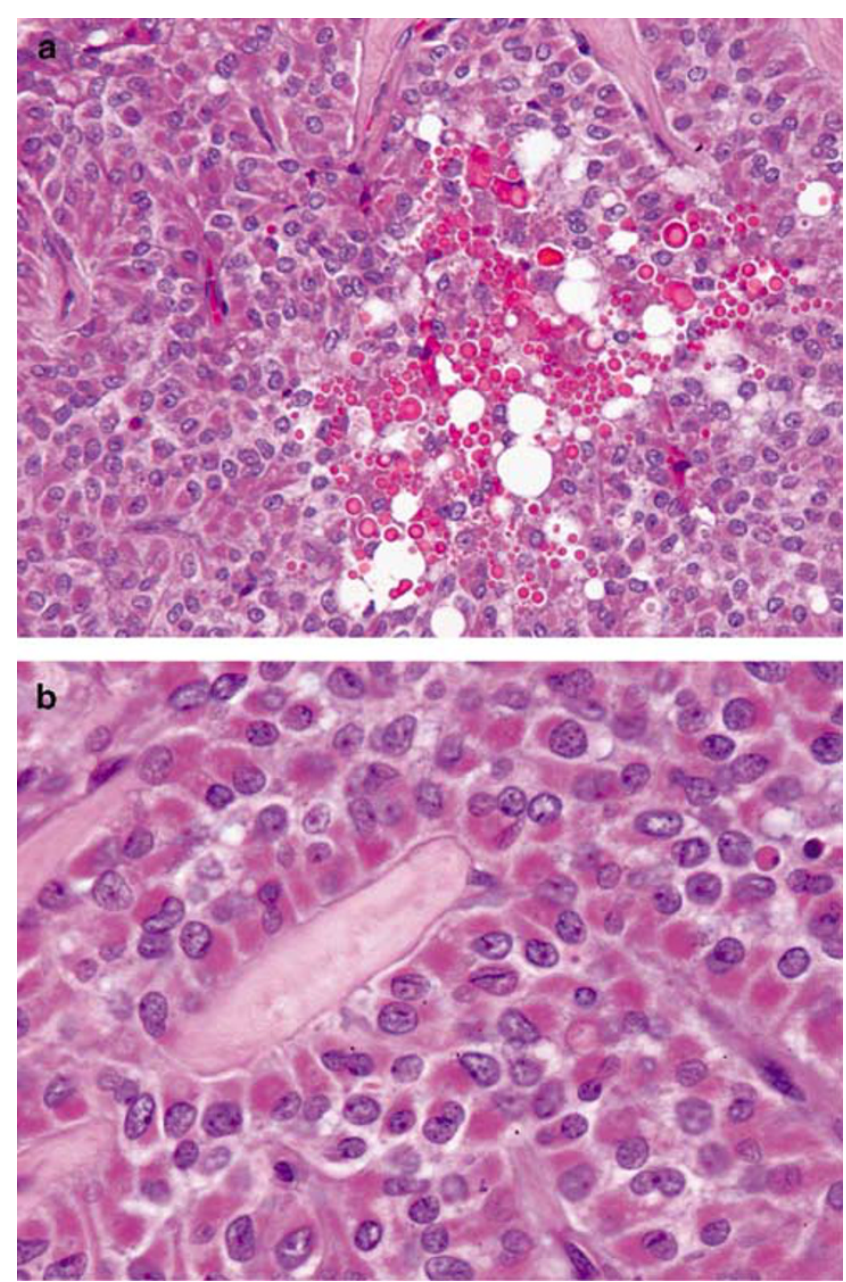

Figure 20 Solid pseudopapillary neoplasm. Aggregates of large hyaline globules are present (a). The nuclei are oval and exhibit longitudinal grooves (b).

(Figure 21), ${ }^{169,178,182,184-188}$ and the pattern of staining for the last marker parallels the distribution of the hyaline globules. The neoplasms variably express synaptophysin and cytokeratins ${ }^{178,187}$ and are consistently negative for chromogranin, ductal markers (glycoproteins), and acinar markers (trypsin and chymotrypsin). Immunolabeling for $\beta$-catenin demonstrates abnormal nuclear labeling in $>90 \%$ of the tumors, ${ }^{83,182,189}$ and $75 \%$ also express cyclin D1. ${ }^{83,190}$ The pattern of staining is not typical for any normal epithelial cells of the pancreas. There is certainly no evidence for acinar or ductal differentiation, and although the positivity for CD56 and synaptophysin might suggest an endocrine phenotype, the most specific endocrine marker (chromogranin) is always negative.

By electron microscopy solid-pseudopapillary neoplasms show epithelial differentiation including an incomplete basal lamina, rudimentary lumina, and poorly defined intercellular junctions. ${ }^{178,184,191-194}$ The neoplastic cells usually contain numerous mitochondria, abundant rough

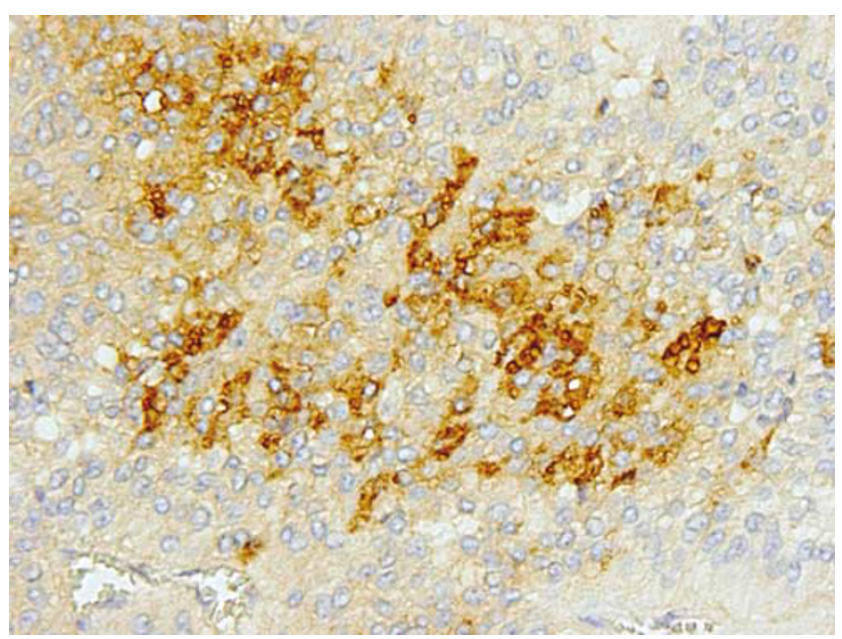

Figure 21 Solid pseudopapillary neoplasm. Immunohistochemical staining for alpha-1-antitrypsin reveals granular staining corresponding to the hyaline globules.

endoplasmic reticulum, and some annulate lamellae. ${ }^{184,191,193,195}$ Most cases also have large $(500-3000 \mathrm{~nm})$ membrane-bound electron dense granules that contain internal granular and membranous debris, resembling the contents of complex secondary lysosomes. Immunoelectron microscopic studies have demonstrated the presence of $\alpha-1$ antitrypsin within these granules, confirming that they correspond to the eosinophilic hyaline globules identified by light microscopy. ${ }^{82}$

Solid-pseudopapillary neoplasms lack the genetic alterations of infiltrating ductal adenocarcinomas (KRAS, p16, DPC4, and p53 genes). ${ }^{53,83,186,190,196-198}$ Almost all, however, have somatic point mutations in exon 3 of the $\beta$-catenin gene, ${ }^{83,189}$ implicating the same genetic pathway that is abnormal in acinar neoplasms (acinar cell carcinoma and pancreatoblastoma). As expected in the presence of $\beta$-catenin activation, solid-pseudopapillary neoplasms typically have cyclin D1 overexpression. ${ }^{83}$

Although solid-pseudopapillary neoplasm is regarded to be malignant, it is extremely indolent. Complete surgical resection results in a cure in the majority of patients. ${ }^{169,191}$ Only $10-15 \%$ of all patients have metastases that are usually present at the time of first diagnosis. ${ }^{169}$ When present, metastases are usually limited to the liver and peritoneum, lymph node metastases being exceptional. ${ }^{82,169,170,175,191,199}$ Even patients with metastases generally survive for years or even decades, and it is uncommon for patients to die from direct effects of the tumor. ${ }^{180,200,201}$ However, the two patients with apparent high-grade malignant transformation of solid-pseudopapillary neoplasms had a highly aggressive course, dying after 6 and 16 months, respectively. ${ }^{183}$

The differential diagnosis again includes the other solid, cellular pancreatic neoplasms (PEN, acinar cell carcinoma, pancreatoblastoma). The finding of 
true luminal spaces is helpful to suggest one of these rather than solid-pseudopapillary neoplasm. In difficult cases, staining for trypsin, chymotrypsin, and chromogranin will usually help confirm one of the alternative diagnoses, and if these markers are all negative, positive staining for vimentin, CD10, CD56, and $\alpha$-1-antitrypsin should be sufficient to confirm the diagnosis. One entity that can cause diagnostic difficulty is pseudocyst. The degenerative changes of solid-pseudopapillary neoplasms can result in a gross and microscopic pattern almost indistinguishable from a pseudocyst. The occurrence of a lesion in a young female without a history of pancreatitis or other predispositions to a pseudocyst indicates that a thorough search for residual tumor should be performed.

\section{References}

1 Heitz PU, Komminoth P, Perren A, et al. Pancreatic endocrine tumours: introduction. In: DeLellis RA, Lloyd RV, Heitz PU, Eng C (eds). Pathology and Genetics of Tumours of Endocrine Organs. IARC Press: Lyon, 2004, pp 177-182.

2 Klimstra DS, Perren A, Oberg K, et al. Pancreatic endocrine tumors: non-functioning tumours and microadenomas. In: DeLellis RA, Lloyd R, Heitz PU, Eng C (eds). Pathology and Genetics of Tumours of Endocrine Organs. IARC Press: Lyon, 2004, pp 201-204.

3 Kimura W, Kuroda A, Morioka Y. Clinical pathology of endocrine tumors of the pancreas. Analysis of autopsy cases. Dig Dis Sci 1991;36:933-942.

4 Solcia E, Capella C, Kloppel G. Atlas of Tumor Pathology. Fascicle 20, Third Series. Armed Forces Institute of Pathology: Washington, DC, 1997.

5 Kloppel G, Willemer S, Stamm B, et al. Pancreatic lesions and hormonal profile of pancreatic tumors in multiple endocrine neoplasia type I. An immunocytochemical study of nine patients. Cancer 1986;57: 1824-1832.

6 Stabile BE, Morrow DJ, Passaro Jr E. The gastrinoma triangle: operative implications. Am J Surg 1984;147: 25-31.

7 Tanaka T, Mori H, Williams GM. Atypical and neoplastic acinar cell lesions of the pancreas in an autopsy study of Japanese patients. Cancer 1988;61: 2278-2285.

8 Bartow SA, Mukai K, Rosai J. Pseudoneoplastic proliferation of endocrine cells in pancreatic fibrosis. Cancer 1981;47:2627-2633.

9 Hochwald SN, Zee S, Conlon KC, et al. Prognostic factors in pancreatic endocrine neoplasms: an analysis of 136 cases with a proposal for low-grade and intermediate-grade groups. J Clin Oncol 2002;20: 2633-2642.

10 Mukai K, Grotting JC, Greider MH, et al. Retrospective study of 77 pancreatic endocrine tumors using the immunoperoxidase method. Am J Surg Pathol 1982;6: $387-399$.

11 Larsson LI, Schwartz T, Lundqvist G, et al. Occurrence of human pancreatic polypeptide in pancreatic endocrine tumors. Possible implication in the watery diarrhea syndrome. Am J Pathol 1976;85:675-684.
12 Tomita T, Kimmel JR, Friesen SR, et al. Pancreatic polypeptide in islet cell tumors. Morphologic and functional correlations. Cancer 1985;56:1649-1657.

13 Moldow RE, Connelly RR. Epidemiology of pancreatic cancer in Conneticut. Gastroenterology 1968;55: 677-686.

14 Clark ES, Carney JA. Pancreatic islet cell tumor associated with Cushing's syndrome. Am J Surg Pathol 1984;8:917-924.

15 Doppman JL, Nieman LK, Cutler Jr GB, et al. Adrenocorticotropic hormone-secreting islet cell tumors: are they always malignant? Radiology 1994; 190:59-64.

16 Gordon DL, Lo MC, Schwartz MA. Carcinoid of the pancreas. Am J Med 1971;51:412-415.

17 Heitz PU, Kasper M, Polak JM, et al. Pancreatic endocrine tumors. Hum Pathol 1982;13:263-271.

18 Kent III RB, van Heerden JA, Weiland LH. Nonfunctioning islet cell tumors. Ann Surg 1981;193:185-190.

19 Le Bodic MF, Heymann MF, Lecomte $\mathrm{M}$, et al. Immunohistochemical study of 100 pancreatic tumors in 28 patients with multiple endocrine neoplasia, type I. Am J Surg Pathol 1996;20:1378-1384.

20 Gumbs AA, Moore PS, Falconi M, et al. Review of the clinical, histological, and molecular aspects of pancreatic endocrine neoplasms. J Surg Oncol 2002;81: 45-53; discussion 4.

21 Libutti SK, Choyke PL, Bartlett DL, et al. Pancreatic neuroendocrine tumors associated with von Hippel Lindau disease: diagnostic and management recommendations. Surgery 1998;124:1153-1159.

22 Hoang MP, Hruban RH, Albores-Saavedra J. Clear cell endocrine pancreatic tumor mimicking renal cell carcinoma: a distinctive neoplasm of von HippelLindau disease. Am J Surg Pathol 2001;25:602-609.

23 Ligneau B, Lombard-Bohas C, Partensky C, et al. Cystic endocrine tumors of the pancreas: clinical, radiologic, and histopathologic features in 13 cases. Am J Surg Pathol 2001;25:752-760.

24 Kloppel G, Heitz PU, Capella C, et al. Endocrine tumours of the pancreas. In: Solicia E, Kloppel G, Sobin LH (eds). Histological Typing of Endocrine Tumours. Sprigner-Verlag: Heidelberg, 2000, pp 56-60.

25 Westermark P, Wernstedt C, Wilander E, et al. A novel peptide in the calcitonin gene related peptide family as an amyloid fibril protein in the endocrine pancreas. Biochem Biophys Res Commun 1986;140: 827-831.

26 Hussain S, Arwini A, Chetty R, et al. Oncocytic pancreatic endocrine neoplasms: a clinicopathologic and immunohistochemical analysis of 21 cases. Mod Pathol 2005;18:279A.

27 Carstens PH, Cressman Jr FK. Malignant oncocytic carcinoid of the pancreas. Ultrastruct Pathol 1989;13: 69-75.

28 Gotchall J, Traweek ST, Stenzel P. Benign oncocytic endocrine tumor of the pancreas in a patient with polyarteritis nodosa. Hum Pathol 1987;18:967-969.

29 Pacchioni D, Papotti M, Macri L, et al. Pancreatic oncocytic endocrine tumors. Cytologic features of two cases. Acta Cytol 1996;40:742-746.

30 Zee SY, Hochwald SN, Conlon KC, et al. Pleomorphic pancreatic endocrine neoplasms: a variant commonly confused with adenocarcinoma. Am J Surg Pathol 2005;29:1194-1200.

31 Deshpande V, Selig MK, Nielsen GP, et al. Ductulo-insular pancreatic endocrine neoplasms: 
clinicopathologic analysis of a unique subtype of pancreatic endocrine neoplasms. Am J Surg Pathol 2003;27:461-468.

32 Reid JD, Yuh SL, Petrelli M, et al. Ductuloinsular tumors of the pancreas: a light, electron microscopic and immunohistochemical study. Cancer 1982;49: 908-915.

33 van Eeden S, de Leng WW, Offerhaus GJ, et al. Ductuloinsular tumors of the pancreas: endocrine tumors with entrapped nonneoplastic ductules. Am J Surg Pathol 2004;28:813-820.

34 Lloyd RV, Mervak T, Schmidt K, et al. Immunohistochemical detection of chromogranin and neuronspecific enolase in pancreatic endocrine neoplasms. Am J Surg Pathol 1984;8:607-614.

35 Larsson LI, Grimelius L, Hakanson R, et al. Mixed endocrine pancreatic tumors producing several peptide hormones. Am J Pathol 1975;79:271-284.

36 Liu TH, Tseng HC, Zhu Y, et al. Insulinoma. An immunocytochemical and morphologic analysis of 95 cases. Cancer 1985;56:1420-1429.

37 Kamisawa T, Tu Y, Egawa N, et al. Ductal and acinar differentiation in pancreatic endocrine tumors. Dig Dis Sci 2002;47:2254-2261.

38 Yantiss RK, Chang HK, Farraye FA, et al. Prevalence and prognostic significance of acinar cell differentiation in pancreatic endocrine tumors. Am J Surg Pathol 2002;26:893-901.

39 Klimstra DS, Rosai J, Heffess CS. Mixed acinar-endocrine carcinomas of the pancreas. Am J Surg Pathol 1994;18:765-778.

40 Arihiro K, Inai K. Malignant islet cell tumor of the pancreas with multiple hormone production and expression of CEA and CA19-9. Report of an autopsy case. Acta Pathol Jpn 1991;41:150-157.

41 Goto A, Niki T, Terado Y, et al. Prevalence of CD99 protein expression in pancreatic endocrine tumours (PETs). Histopathology 2004;45:384-392.

42 Viale G, Doglioni C, Gambacorta M, et al. Progesterone receptor immunoreactivity in pancreatic endocrine tumors. An immunocytochemical study of 156 neuroendocrine tumors of the pancreas, gastrointestinal and respiratory tracts, and skin. Cancer 1992; 70:2268-2277.

43 Pelosi G, Bresaola E, Bogina G, et al. Endocrine tumors of the pancreas: Ki-67 immunoreactivity on paraffin sections is an independent predictor for malignancy: a comparative study with proliferating-cell nuclear antigen and progesterone receptor protein immunostaining, mitotic index, and other clinicopathologic variables. Hum Pathol 1996;27: 1124-1134.

44 Speel EJ, Richter J, Moch H, et al. Genetic differences in endocrine pancreatic tumor subtypes detected by comparative genomic hybridization. Am J Pathol 1999;155:1787-1794.

45 Stumpf E, Aalto Y, Hoog A, et al. Chromosomal alterations in human pancreatic endocrine tumors. Genes Chromosomes Cancer 2000;29:83-87.

46 Zhao J, Moch H, Scheidweiler AF, et al. Genomic imbalances in the progression of endocrine pancreatic tumors. Genes Chromosomes Cancer 2001;32: 364-372.

47 Asteria C, Anagni M, Fugazzola L, et al. MEN1 gene mutations are a rare event in patients with sporadic neuroendocrine tumors. Eur J Intern Med 2002;13: 319-323.
48 Cupisti K, Hoppner W, Dotzenrath C, et al. Lack of MEN1 gene mutations in 27 sporadic insulinomas. Eur J Clin Invest 2000;30:325-329.

49 Gortz B, Roth J, Krahenmann A, et al. Mutations and allelic deletions of the MEN1 gene are associated with a subset of sporadic endocrine pancreatic and neuroendocrine tumors and not restricted to foregut neoplasms. Am J Pathol 1999;154:429-436.

50 Hessman O, Lindberg D, Einarsson A, et al. Genetic alterations on $3 p, 11 q 13$, and $18 q$ in nonfamilial and MEN 1-associated pancreatic endocrine tumors. Genes Chromosomes Cancer 1999;26:258-264.

51 Komminoth P. Review: multiple endocrine neoplasia type 1, sporadic neuroendocrine tumors, and MENIN. Diagn Mol Pathol 1999;8:107-112.

52 Moore PS, Missiaglia E, Antonello D, et al. Role of disease-causing genes in sporadic pancreatic endocrine tumors: MEN1 and VHL. Genes Chromosomes Cancer 2001;32:177-181.

53 Moore PS, Orlandini S, Zamboni G, et al. Pancreatic tumours: molecular pathways implicated in ductal cancer are involved in ampullary but not in exocrine nonductal or endocrine tumorigenesis. $\mathrm{Br} \mathrm{J}$ Cancer 2001;84:253-262.

54 Shan L, Nakamura Y, Nakamura M, et al. Somatic mutations of multiple endocrine neoplasia type 1 gene in the sporadic endocrine tumors. Lab Invest 1998;78:471-475.

55 Wang EH, Ebrahimi SA, Wu AY, et al. Mutation of the MENIN gene in sporadic pancreatic endocrine tumors. Cancer Res 1998;58:4417-4420.

56 Zhuang Z, Vortmeyer AO, Pack S, et al. Somatic mutations of the MEN1 tumor suppressor gene in sporadic gastrinomas and insulinomas. Cancer Res 1997;57:4682-4686.

57 Lubensky IA, Pack S, Ault D, et al. Multiple neuroendocrine tumors of the pancreas in von Hippel-Lindau disease patients: histopathological and molecular genetic analysis. Am J Pathol 1998; 153:223-231.

58 Chung DC, Smith AP, Louis DN, et al. A novel pancreatic endocrine tumor suppressor gene locus on chromosome $3 p$ with clinical prognostic implications. J Clin Invest 1997;100:404-410.

59 Pellegata NS, Sessa F, Renault B, et al. K-ras and p53 gene mutations in pancreatic cancer: ductal and nonductal tumors progress through different genetic lesions. Cancer Res 1994;54:1556-1560.

60 House MG, Herman JG, Guo MZ, et al. Aberrant hypermethylation of tumor suppressor genes in pancreatic endocrine neoplasms. Ann Surg 2003; 238:423-431; discussion 31-32.

61 Muscarella P, Melvin WS, Fisher WE, et al. Genetic alterations in gastrinomas and nonfunctioning pancreatic neuroendocrine tumors: an analysis of p16/ MTS1 tumor suppressor gene inactivation. Cancer Res 1998;58:237-240.

62 Serrano J, Goebel SU, Peghini PL, et al. Alterations in the p16INK4a/CDKN2A tumor suppressor gene in gastrinomas. J Clin Endocrinol Metab 2000;85: 4146-4156.

63 Perren A, Roth J, Muletta-Feurer S, et al. Clonal analysis of sporadic pancreatic endocrine tumours. J Pathol 1998;186:363-371.

64 Brentjens R, Saltz L. Islet cell tumors of the pancreas: the medical oncologist's perspective. Surg Clin North Am 2001;81:527-542. 
65 Dial PF, Braasch JW, Rossi RL, et al. Management of nonfunctioning islet cell tumors of the pancreas. Surg Clin North Am 1985;65:291-299.

66 Eckhauser FE, Cheung PS, Vinik AI, et al. Nonfunctioning malignant neuroendocrine tumors of the pancreas. Surgery 1986;100:978-988.

67 Liu TH, Zhu Y, Cui QC, et al. Nonfunctioning pancreatic endocrine tumors. An immunohistochemical and electron microscopic analysis of 26 cases. Pathol Res Pract 1992;188:191-198.

68 Venkatesh S, Ordonez NG, Ajani J, et al. Islet cell carcinoma of the pancreas. A study of 98 patients. Cancer 1990;65:354-357.

69 La Rosa S, Sessa F, Capella C, et al. Prognostic criteria in nonfunctioning pancreatic endocrine tumours. Virchows Arch 1996;429:323-333.

70 Bottger T, Seidl C, Seifert JK, et al. Value of quantitative DNA analysis in endocrine tumors of the pancreas. Oncology 1997;54:318-323.

71 Kenny BD, Sloan JM, Hamilton PW, et al. The role of morphometry in predicting prognosis in pancreatic islet cell tumors. Cancer 1989;64:460-465.

72 Clarke MR, Baker EE, Weyant RJ, et al. Proliferative activity in pancreatic endocrine tumors: association with function, metastases, and survival. Endocr Pathol 1997;8:181-187.

73 Wild A, Langer P, Celik I, et al. Chromosome 22q in pancreatic endocrine tumors: identification of a homozygous deletion and potential prognostic associations of allelic deletions. Eur J Endocrinol 2002; 147:507-513.

74 Rigaud G, Missiaglia E, Moore PS, et al. High resolution allelotype of nonfunctional pancreatic endocrine tumors: identification of two molecular subgroups with clinical implications. Cancer Res 2001;61:285-292.

75 Imam H, Eriksson B, Oberg K. Expression of CD44 variant isoforms and association to the benign form of endocrine pancreatic tumours. Ann Oncol 2000;11: 295-300.

76 Komminoth $\mathrm{P}$, Seelentag WK, Saremaslani P, et al. CD44 isoform expression in the diffuse neuroendocrine system. II. Benign and malignant tumors. Histochem Cell Biol 1996;106:551-562.

77 Deshpande V, Fernandez-del Castillo C, Muzikansky A, et al. Cytokeratin 19 is a powerful predictor of survival in pancreatic endocrine tumors. Am J Surg Pathol 2004;28:1145-1153.

78 Klimstra DS, Heffess CS, Oertel JE, et al. Acinar cell carcinoma of the pancreas. A clinicopathologic study of 28 cases. Am J Surg Pathol 1992;16: 815-837.

79 Klimstra DS, Wenig BM, Adair CF, et al. Pancreatoblastoma. A clinicopathologic study and review of the literature. Am J Surg Pathol 1995;19:1371-1389.

80 Ordonez NG. Pancreatic acinar cell carcinoma. Adv Anat Pathol 2001;8:144-159.

81 Pitman MB, Faquin WC. The fine-needle aspiration biopsy cytology of pancreatoblastoma. Diagn Cytopathol 2004;31:402-406.

82 Klimstra DS, Wenig BM, Heffess CS. Solid-pseudopapillary tumor of the pancreas: a typically cystic carcinoma of low malignant potential. Semin Diagn Pathol 2000;17:66-80.

83 Abraham SC, Klimstra DS, Wilentz RE, et al. Solid-pseudopapillary tumors of the pancreas are genetically distinct from pancreatic ductal adenocarcinomas and almost always harbor betacatenin mutations. Am J Pathol 2002;160:1361-1369.

84 Bordi C, Oberg K, Papotti M, et al. Pancreatic endocrine tumours: poorly differentiated endocrine carcinoma. In: DeLellis RA, Lloyd RV, Heitz PU, Eng $C$ (eds). Pathology and Genetics of Tumours of Endocrine Organs. IARC Press: Lyon, 2004, pp 207-208.

85 Reyes CV, Wang T. Undifferentiated small cell carcinoma of the pancreas: a report of five cases. Cancer 1981;47:2500-2502.

86 Corrin B, Gilby ED, Jones NF, et al. Oat cell carcinoma of the pancreas with ectopic ACTH secretion. Cancer 1973;31:1523-1527.

87 Hobbs RD, Stewart AF, Ravin ND, et al. Hypercalcemia in small cell carcinoma of the pancreas. Cancer 1984;53:1552-1554

88 Chetty R, Clark SP, Pitson GA. Primary small cell carcinoma of the pancreas. Pathology 1993;25: 240-242.

89 O'Connor TP, Wade TP, Sunwoo YC, et al. Small cell undifferentiated carcinoma of the pancreas. Report of a patient with tumor marker studies. Cancer 1992;70:1514-1519.

90 Nassar H, Albores-Saavedra J, Klimstra DS. Highgrade neuroendocrine carcinoma of the ampulla of vater: a clinicopathologic and immunohistochemical analysis of 14 cases. Am J Surg Pathol 2005;29: 588-594.

91 Movahedi-Lankarani S, Hruban RH, Westra WH, et al. Primitive neuroectodermal tumors of the pancreas: a report of seven cases of a rare neoplasm. Am J Surg Pathol 2002;26:1040-1047.

92 Bismar TA, Basturk O, Gerald WL, et al. Desmoplastic small cell tumor in the pancreas. Am J Surg Pathol 2004;28:808-812.

93 Klimstra DS. Cell lineage in pancreatic neoplasms. In: Sarkar FH, Dugan MC (eds). Pancreatic Cancer: Advances in Molecular Pathology, Diagnosis and Clinical Management. BioTechniques Books: Natick, 1998, pp 21-47.

94 Albores-Saavedra J. Acinar cystadenoma of the pancreas: a previously undescribed tumor. Ann Diagn Pathol 2002;6:113-115.

95 Zamboni G, Terris B, Scarpa A, et al. Acinar cell cystadenoma of the pancreas: a new entity? Am J Surg Pathol 2002;26:698-704.

96 Chatelain D, Paye F, Mourra N, et al. Unilocular acinar cell cystadenoma of the pancreas an unusual acinar cell tumor. Am J Clin Pathol 2002;118: 211-214.

97 Holen K, Klimstra DS, Hummer A, et al. Clinical characteristics and outcomes from an institutional series of acinar cell carcinoma of the pancreas. J Clin Oncol 2002;20:4673-4678.

98 Hoorens A, Lemoine NR, McLellan E, et al. Pancreatic acinar cell carcinoma. An analysis of cell lineage markers, p53 expression, and Ki-ras mutation. Am J Pathol 1993;143:685-698.

99 Mizuta $\mathrm{Y}$, Isomoto $\mathrm{H}$, Futuki $\mathrm{Y}$, et al. Acinar cell carcinoma of the pancreas associated with hypoglycemia: involvement of 'big' insulin-like growth factorII. J Gastroenterol 1998;33:761-765.

100 Burns WA, Matthews MJ, Hamosh M, et al. Lipasesecreting acinar cell carcinoma of the pancreas with polyarthropathy. A light and electron microscopic, histochemical, and biochemical study. Cancer 1974;33:1002-1009. 
101 Klimstra DS. Acinar cell carcinoma of the pancreas. A case associated with the lipase hypersecretion syndrome. Pathol Case Rev 2001;6:121-126.

102 Radin DR, Colletti PM, Forrester DM, et al. Pancreatic acinar cell carcinoma with subcutaneous and intraosseous fat necrosis. Radiology 1986;158:67-68.

103 Kuerer H, Shim H, Pertsemlidis D, et al. Functioning pancreatic acinar cell carcinoma: immunohistochemical and ultrastructural analyses. Am J Clin Oncol 1997;20:101-107.

104 Good AE, Schnitzer B, Kawanishi H, et al. Acinar pancreatic tumor with metastatic fat necrosis: report of a case and review of rheumatic manifestations. Am J Dig Dis 1976;21:978-987.

105 Cingolani N, Shaco-Levy R, Farruggio A, et al. Alphafetoprotein production by pancreatic tumors exhibiting acinar cell differentiation: study of five cases, one arising in a mediastinal teratoma. Hum Pathol 2000;31:938-944.

106 Itoh T, Kishi K, Tojo M, et al. Acinar cell carcinoma of the pancreas with elevated serum alphafetoprotein levels: a case report and a review of 28 cases reported in Japan. Gastroenterol Jpn 1992;27: 785-791.

107 Nojima T, Kojima T, Kato H, et al. Alpha-fetoproteinproducing acinar cell carcinoma of the pancreas. Hum Pathol 1992;23:828-830.

108 Ono J, Sakamoto H, Sakoda K, et al. Acinar cell carcinoma of the pancreas with elevated serum alphafetoprotein. Int Surg 1984;69:361-364.

109 Shimoike T, Goto M, Nakano I, et al. Acinar-islet cell carcinoma presenting as insulinoma. J Gastroenterol 1997;32:830-835.

110 Cantrell BB, Cubilla AL, Erlandson RA, et al. Acinar cell cystadenocarcinoma of human pancreas. Cancer 1981;47:410-416.

111 Colombo P, Arizzi C, Roncalli M. Acinar cell cystadenocarcinoma of the pancreas: report of rare case and review of the literature. Hum Pathol 2004;35:1568-1571.

112 Stamm B, Burger H, Hollinger A. Acinar cell cystadenocarcinoma of the pancreas. Cancer 1987;60: 2542-2547.

113 Morohoshi T, Kanda M, Horie A, et al. Immunocytochemical markers of uncommon pancreatic tumors. Acinar cell carcinoma, pancreatoblastoma, and solid cystic (papillary-cystic) tumor. Cancer 1987;59: 739-747.

114 Ishizaki A, Koito K, Namieno T, et al. Acinar cell carcinoma of the pancreas: a rare case of an alphafetoprotein-producing cystic tumor. Eur J Radiol 1995;21:58-60.

115 Ohike N, Kosmahl M, Kloppel G. Mixed acinarendocrine carcinoma of the pancreas. A clinicopathological study and comparison with acinar-cell carcinoma. Virchows Arch 2004;445:231-235.

116 Shinagawa T, Tadokoro M, Maeyama S, et al. Alpha fetoprotein-producing acinar cell carcinoma of the pancreas showing multiple lines of differentiation. Virchows Arch 1995;426:419-423.

117 Horie A, Morohoshi T, Kloppel G. Ultrastructural comparison of pancreatoblastoma, solid cystic tumor and acinar cell carcinoma. J Clin Electron Microsc 1987;20:353-362.

118 Tucker JA, Shelburne JD, Benning TL, et al. Filamentous inclusions in acinar cell carcinoma of the pancreas. Ultrastruct Pathol 1994;18:279-286.
119 Caruso RA, Inferrera A, Tuccari G, et al. Acinar cell carcinoma of the pancreas. A histologic, immunocytochemical and ultrastructural study. Histol Histopathol 1994;9:53-58.

120 Ordonez NG, Mackay B. Acinar cell carcinoma of the pancreas. Ultrastruct Pathol 2000;24:227-241.

121 Pasquinelli G, Preda P, Martinelli GN, et al. Filamentous inclusions in nonneoplastic and neoplastic pancreas: an ultrastructural and immunogold labeling study. Ultrastruct Pathol 1995;19:495-500.

122 Toyota N, Takada T, Ammori BJ, et al. Acinar cell carcinoma of the pancreas showing finger-print-like zymogen granules by electron microscopy: immunohistochemical study. J Hepatobiliary Pancreat Surg 2000;7:102-106.

123 Moore PS, Beghelli S, Zamboni G, et al. Genetic abnormalities in pancreatic cancer. Mol Cancer 2003;2:7.

124 Longnecker DS. Molecular pathology of invasive carcinoma. Ann N Y Acad Sci 1999;880:74-82.

125 Terhune PG, Heffess CS, Longnecker DS. Only wildtype c-Ki-ras codons 12, 13, and 61 in human pancreatic acinar cell carcinomas. Mol Carcinog 1994;10:110-114.

126 Abraham SC, Wu TT, Hruban RH, et al. Genetic and immunohistochemical analysis of pancreatic acinar cell carcinoma: frequent allelic loss on chromosome $11 \mathrm{p}$ and alterations in the APC/beta-catenin pathway. Am J Pathol 2002;160:953-962.

127 Holen KD, Klimstra DS, Hummer A, et al. Clinical characteristics and outcomes from an institutional series of acinar cell carcinoma of the pancreas and related tumors. J Clin Oncol 2002;20:4673-4678.

128 Hassan MO, Gogate PA. Malignant mixed exocrineendocrine tumor of the pancreas with unusual intracytoplasmic inclusions. Ultrastruct Pathol 1993;17:483-493.

129 Cho KJ, Kim JY, Lee SS, et al. Mixed acinar-endocrine carcinoma of the pancreas-a case report. J Korean Med Sci 1996;11:188-192.

130 Frank M, Bittinger A, Rothmund M, et al. Immunohistochemical analysis and clinical course of highmalignant composite endocrine-acinar cell carcinoma: a case report. Pancreas 1998;17:210-212.

131 Muramatsu T, Kijima H, Tsuchida T, et al. Acinar-islet cell tumor of the pancreas: report of a malignant pancreatic composite tumor. J Clin Gastroenterol 2000;31:175-178.

132 Ogawa T, Isaji S, Yabana T. A case of mixed acinarendocrine carcinoma of the pancreas discovered in an asymptomatic subject. Int J Pancreatol 2000;27: 249-257.

133 Tobita K, Kijima H, Chino O, et al. Pancreatic acinar cell carcinoma with endocrine differentiation: immunohistochemical and ultrastructural analyses. Anticancer Res 2001;21:2131-2134.

134 Klimstra DS, Longnecker D. Pancreatoblastoma. In: Hamilton SR, Aaltonen LA (eds). Pathology and Genetics of Tumours of the Digestive System. IARC Press: Lyon, 2000, pp 244-245.

135 Japanese Pancreas Society. Classification of pancreatic carcinoma, 2nd English edn. Kanehara \& Co., Ltd.: Tokyo, 2003.

136 Shorter NA, Glick RD, Klimstra DS, et al. Malignant pancreatic tumors in childhood and adolescence: the Memorial Sloan-Kettering experience, 1967 to present. J Pediatr Surg 2002;37:887-892. 
137 Jaksic T, Yaman M, Thorner P, et al. A 20-year review of pediatric pancreatic tumors. J Pediatr Surg 1992; 27:1315-1317.

138 Cubilla AL, Fitzgerald PJ. Morphological patterns of primary nonendocrine human pancreas carcinoma. Cancer Res 1975;35:2234-2248.

139 Hoorens A, Gebhard F, Kraft K, et al. Pancreatoblastoma in an adult: its separation from acinar cell carcinoma. Virchows Arch 1994;424:485-490.

140 Horie A. Pancreatoblastoma: histopathologic criteria based upon a review of six cases. Cancer Treat Res 1982;8:159-166.

141 Horie A, Haratake J, Jimi A, et al. Pancreatoblastoma in Japan, with differential diagnosis from papillary cystic tumor (ductuloacinar adenoma) of the pancreas. Acta Pathol Jpn 1987;37:47-63.

142 Kissane JM. Pancreatoblastoma and solid and cystic papillary tumor: two tumors related to pancreatic ontogeny. Semin Diagn Pathol 1994;11:152-164.

143 Chun Y, Kim W, Park K, et al. Pancreatoblastoma. J Pediatr Surg 1997;32:1612-1615.

144 Dhebri AR, Connor S, Campbell F, et al. Diagnosis, treatment and outcome of pancreatoblastoma. Pancreatology 2004;4:441-451; discussion 52-3.

145 Dunn JL, Longnecker DS. Pancreatoblastoma in an older adult. Arch Pathol Lab Med 1995;119: $547-551$.

146 Levey JM, Banner BF. Adult pancreatoblastoma: a case report and review of the literature. Am J Gastroenterol 1996;91:1841-1844.

147 Drut R, Jones MC. Congenital pancreatoblastoma in Beckwith-Wiedemann syndrome: an emerging association. Pediatr Pathol 1988;8:331-339.

148 Kerr NJ, Chun YH, Yun K, et al. Pancreatoblastoma is associated with chromosome 11p loss of heterozygosity and IGF2 overexpression. Med Pediatr Oncol 2002;39:52-54.

149 Koh TH, Cooper JE, Newman CL, et al. Pancreatoblastoma in a neonate with Wiedemann-Beckwith syndrome. Eur J Pediatr 1986;145:435-438.

150 Potts SR, Brown S, O’Hara MD. Pancreoblastoma in a neonate associated with Beckwith-Wiedemann syndrome. Z Kinderchir 1986;41:56-57.

151 Abraham SC, Wu TT, Klimstra DS, et al. Distinctive molecular genetic alterations in sporadic and familial adenomatous polyposis-associated pancreatoblastomas: frequent alterations in the APC/beta-catenin pathway and chromosome 11p. Am J Pathol 2001; 159:1619-1627.

152 Buchino JJ, Castello FM, Nagaraj HS. Pancreatoblastoma. A histochemical and ultrastructural analysis. Cancer 1984;53:963-969.

153 Morohoshi T, Sagawa F, Mitsuya T. Pancreatoblastoma with marked elevation of serum alpha-fetoprotein. An autopsy case report with immunocytochemical study. Virchows Arch A Pathol Anat Histopathol 1990;416:265-270.

154 Ogawa B, Okinaga K, Obana K, et al. Pancreatoblastoma treated by delayed operation after effective chemotherapy. J Pediatr Surg 2000;35: 1663-1665.

155 Ohaki Y, Misugi K, Fukuda J, et al. Immunohistochemical study of pancreatoblastoma. Acta Pathol Jpn 1987;37:1581-1590.

156 Iseki M, Suzuki T, Koizumi Y, et al. Alpha-fetoprotein-producing pancreatoblastoma. A case report. Cancer 1986;57:1833-1835.
157 Chan MH, Shing MM, Poon TC, et al. Alphafetoprotein variants in a case of pancreatoblastoma. Ann Clin Biochem 2000;37(Part 5):681-685.

158 Henke AC, Kelley CM, Jensen CS, et al. Fine-needle aspiration cytology of pancreatoblastoma. Diagn Cytopathol 2001;25:118-121.

159 Kawamoto K, Matsuo T, Jubashi T, et al. Primary pancreatic carcinoma in childhood. Pancreatoblastoma. Acta Pathol Jpn 1985;35:137-143.

160 Nishimata S, Kato K, Tanaka M, et al. Expression pattern of keratin subclasses in pancreatoblastoma with special emphasis on squamoid corpuscles. Pathol Int 2005;55:297-302.

161 Silverman JF, Holbrook CT, Pories WJ, et al. Fine needle aspiration cytology of pancreatoblastoma with immunocytochemical and ultrastructural studies. Acta Cytol 1990;34:632-640.

162 Tanaka Y, Kato K, Notohara K, et al. Significance of aberrant (cytoplasmic/nuclear) expression of betacatenin in pancreatoblastoma. J Pathol 2003;199: 185-190.

163 Palosaari D, Clayton F, Seaman J. Pancreatoblastoma in an adult. Arch Pathol Lab Med 1986;110: 650-652.

164 Vannier JP, Flamant F, Hemet J, et al. Pancreatoblastoma: response to chemotherapy. Med Pediatr Oncol 1991:19:187-191.

165 Vossen S, Goretzki PE, Goebel U, et al. Therapeutic management of rare malignant pancreatic tumors in children. World J Surg 1998;22:879-882.

166 Murakami T, Ueki K, Kawakami H, et al. Pancreatoblastoma: case report and review of treatment in the literature. Med Pediatr Oncol 1996;27:193-197.

167 Griffin BR, Wisbeck WM, Schaller RT, et al. Radiotherapy for locally recurrent infantile pancreatic carcinoma (pancreatoblastoma). Cancer 1987;60: 1734-1736

168 Kloppel G, Luttges J, Klimstra DS, et al. Solidpseudopapillary neoplasm. In: Hamilton SR, Aaltonen LA (eds). World Heath Organization Classification of Tumours. Pathology and Genetic of Tumours of the Digestive System. IARC Press: Lyon, 2000, pp 246-248.

169 Martin RC, Klimstra DS, Brennan MF, et al. Solidpseudopapillary tumor of the pancreas: a surgical enigma? Ann Surg Oncol 2002;9:35-40.

170 Lam KY, Lo CY, Fan ST. Pancreatic solid-cysticpapillary tumor: clinicopathologic features in eight patients from Hong Kong and review of the literature. World J Surg 1999;23:1045-1050.

171 Buetow PC, Buck JL, Pantongrag-Brown L, et al. Solid and papillary epithelial neoplasm of the pancreas: imaging-pathologic correlation on 56 cases. Radiology 1996;199:707-711.

172 Matsunou H, Konishi F, Yamamichi N, et al. Solid, infiltrating variety of papillary cystic neoplasm of the pancreas. Cancer 1990;65:2747-2757.

173 Yamaguchi K, Miyagahara T, Tsuneyoshi M, et al. Papillary cystic tumor of the pancreas: an immunohistochemical and ultrastructural study of 14 patients. Jpn J Clin Oncol 1989;19:102-111.

174 Panieri E, Krige JE, Bornman PC, et al. Operative management of papillary cystic neoplasms of the pancreas. J Am Coll Surg 1998;186:319-324.

175 Mao C, Guvendi M, Domenico DR, et al. Papillary cystic and solid tumors of the pancreas: a pancreatic embryonic tumor? Studies of three cases and 
cumulative review of the world's literature. Surgery 1995;118:821-828.

176 Jeng LB, Chen MF, Tang RP. Solid and papillary neoplasm of the pancreas. Emphasis on surgical treatment. Arch Surg 1993;128:433-436.

177 Duff P, Greene VP. Pregnancy complicated by solidpapillary epithelial tumor of the pancreas, pulmonary embolism, and pulmonary embolectomy. Am J Obstet Gynecol 1985;152:80-81.

178 Stommer P, Kraus J, Stolte M, et al. Solid and cystic pancreatic tumors. Clinical, histochemical, and electron microscopic features in ten cases. Cancer 1991;67:1635-1641.

179 Lieber MR, Lack EE, Roberts Jr JR, et al. Solid and papillary epithelial neoplasm of the pancreas. An ultrastructural and immunocytochemical study of six cases. Am J Surg Pathol 1987;11:85-93.

180 Kloppel G, Kosmahl M. Cystic lesions and neoplasms of the pancreas. The features are becoming clearer. Pancreatology 2001;1:648-655.

181 Pettinato G, Manivel JC, Ravetto C, et al. Papillary cystic tumor of the pancreas. A clinicopathologic study of 20 cases with cytologic, immunohistochemical, ultrastructural, and flow cytometric observations, and a review of the literature. Am J Clin Pathol 1992;98:478-488.

182 Kosmahl M, Seada LS, Janig U, et al. Solid-pseudopapillary tumor of the pancreas: its origin revisited. Virchows Arch 2000;436:473-480.

183 Tang LH, Aydin H, Brennan MF, et al. Clinically aggressive solid pseudopapillary tumors of the pancreas: a report of two cases with components of undifferentiated carcinoma and a comparative clinicopathologic analysis of 34 conventional cases. Am J Surg Pathol 2005;29:512-519.

184 Balercia G, Zamboni G, Bogina G, et al. Solid-cystic tumor of the pancreas. An extensive ultrastructural study of fourteen cases. J Submicrosc Cytol Pathol 1995;27:331-340.

185 Miettinen M, Partanen S, Fraki O, et al. Papillary cystic tumor of the pancreas. An analysis of cellular differentiation by electron microscopy and immunohistochemistry. Am J Surg Pathol 1987;11: 855-865.

186 Lee WY, Tzeng CC, Chen RM, et al. Papillary cystic tumors of the pancreas: assessment of malignant potential by analysis of progesterone receptor, flow cytometry, and ras oncogene mutation. Anticancer Res 1997;17:2587-2591.

187 Notohara K, Hamazaki S, Tsukayama C, et al. Solidpseudopapillary tumor of the pancreas: immunohistochemical localization of neuroendocrine markers and CD10. Am J Surg Pathol 2000;24:1361-1371.
188 Zamboni G, Bonetti F, Scarpa A, et al. Expression of progesterone receptors in solid-cystic tumour of the pancreas: a clinicopathological and immunohistochemical study of ten cases. Virchows Arch A Pathol Anat Histopathol 1993;423:425-431.

189 Tanaka Y, Kato K, Notohara K, et al. Frequent betacatenin mutation and cytoplasmic/nuclear accumulation in pancreatic solid-pseudopapillary neoplasm. Cancer Res 2001;61:8401-8404.

190 Muller-Hocker J, Zietz CH, Sendelhofert A. Deregulated expression of cell cycle-associated proteins in solid pseudopapillary tumor of the pancreas. Mod Pathol 2001;14:47-53.

191 Nishihara K, Nagoshi M, Tsuneyoshi M, et al. Papillary cystic tumors of the pancreas. Assessment of their malignant potential. Cancer 1993;71:82-92.

192 Ueda N, Nagakawa T, Ohta T, et al. Clinicopathological studies on solid and cystic tumors of the pancreas. Gastroenterol Jpn 1991;26:497-502.

193 Matsunou H, Konishi F. Papillary-cystic neoplasm of the pancreas. A clinicopathologic study concerning the tumor aging and malignancy of nine cases. Cancer 1990;65:283-291.

194 Hamoudi AB, Misugi K, Grosfeld JL, et al. Papillary epithelial neoplasm of pancreas in a child. Report of a case with electron microscopy. Cancer 1970;26: 1126-1134.

195 Jorgensen LJ, Hansen AB, Burcharth F, et al. Solid and papillary neoplasm of the pancreas. Ultrastruct Pathol 1992;16:659-666.

196 Yamaue H, Tanimura H, Shono Y, et al. Solid and cystic tumor of the pancreas: clinicopathologic and genetic studies of four cases. Int J Pancreatol 2000;27:69-76.

197 Flejou JF, Boulange B, Bernades P, et al. p53 protein expression and DNA ploidy in cystic tumors of the pancreas. Pancreas 1996;13:247-252.

198 Bartsch D, Bastian D, Barth P, et al. K-ras oncogene mutations indicate malignancy in cystic tumors of the pancreas. Ann Surg 1998;228:79-86.

199 Horisawa M, Niinomi N, Sato T, et al. Frantz's tumor (solid and cystic tumor of the pancreas) with liver metastasis: successful treatment and long-term follow-up. J Pediatr Surg 1995;30:724-726.

200 Saiura A, Umekita N, Matsui Y, et al. Successful surgical resection of solid cystic tumor of the pancreas with multiple liver metastases and a tumor thrombus in the portal vein. Hepatogastroenterology 2000;47:887-889.

201 Yoon DY, Hines OJ, Bilchik AJ, et al. Solid and papillary epithelial neoplasms of the pancreas: aggressive resection for cure. Am Surg 2001;67: 1195-1199. 